Article

\title{
Impacts of Manufacturing Specialized and Diversified Agglomeration on the Eco-Innovation Efficiency-A Nonlinear Test from Dynamic Perspective
}

\author{
Lu Zhang ${ }^{1}$, Renyan Mu ${ }^{1, *}$, Shuhua Hu ${ }^{1}$, Quan Zhang ${ }^{1}$ and Song Wang ${ }^{2}$ \\ 1 School of Management, Wuhan University of Technology, Wuhan 430070, China; \\ zhanglu9393@whut.edu.cn (L.Z.); sjxwhsh@whut.edu.cn (S.H.); zhangquanms@whut.edu.cn (Q.Z.) \\ 2 School of Economics and Business Administration, Central China Normal University, Wuhan 430079, China; \\ wangsong@mail.ccnu.edu.cn \\ * Correspondence: murenyan@whut.edu.cn
}

check for updates

Citation: Zhang, L.; Mu, R.; Hu, S.; Zhang, Q.; Wang, S. Impacts of Manufacturing Specialized and Diversified Agglomeration on the Eco-innovation Efficiency-A Nonlinear Test from Dynamic Perspective. Sustainability 2021, 13, 3809. https://doi.org/10.3390/ su13073809

Academic Editor: Erika Loučanová

Received: 21 February 2021

Accepted: 23 March 2021

Published: 30 March 2021

Publisher's Note: MDPI stays neutral with regard to jurisdictional claims in published maps and institutional affiliations.

Copyright: (c) 2021 by the authors. Licensee MDPI, Basel, Switzerland. This article is an open access article distributed under the terms and conditions of the Creative Commons Attribution (CC BY) license (https:/ / creativecommons.org/licenses/by/ $4.0 /)$.

\begin{abstract}
Eco-innovation is the main driver of realizing the coordinated development of resource, environmental and economic systems. This paper measures regional eco-innovation efficiency (EIE) by using the Super-Slack Based Measure (SBM) model with undesirable outputs and distinguishes different agglomeration patterns based on Chinese data of 21 manufacturing sub-industries of 30 provinces. In particular, from the perspective of the dynamic evolution of manufacturing agglomeration, the nonlinear effects of specialized and diversified agglomeration on EIE are investigated based on panel threshold regression models. The results indicate that China's EIE shows a U-shaped changing trend. The impacts of specialized and diversified agglomeration on EIE are nonlinear and have significant three-threshold effects. There exist a U-shaped relationship between specialized agglomeration and EIE, and an S-shaped relationship between diversified agglomeration and EIE. In terms of eco-innovation, the development of diversified agglomeration is superior to that of specialized agglomeration. Overall, there is still much room for more than $70 \%$ of provinces in China to increase their EIE by optimizing the layout of manufacturing specialized and diversified agglomeration. To improve the EIE and achieve sustainable economic growth, differentiated agglomeration policies should be formulated in various stages and regions. In addition, the driving mechanism of eco-innovation should be strengthened.
\end{abstract}

Keywords: specialized agglomeration; diversified agglomeration; eco-innovation efficiency; manufacturing industry; panel threshold regression; nonlinear effects

\section{Introduction}

Rapid industrialization and urbanization in developing countries have consumed many extensive resources, causing increasingly serious ecological problems such as environmental pollution and energy shortages, especially in China [1]. In 2019, China's GDP ranked second in the world, but according to the 2020 World Environmental Performance Index Report issued by Yale University and other units, its environmental performance ranked only 120th among 180 countries [2]. The increasingly prominent contradiction between economy and ecology has greatly restricted the sustainable development of China [3]. In this context, eco-innovation harmonizing economic growth and the limits of resources and environment receives widespread attention from all walks of life $[4,5]$.

Eco-innovation is one innovation aiming at reducing the adverse effects of economic activities on the environment and achieving more efficient use of natural resources $[6,7]$. Terms synonymous with eco-innovation include environmental innovation [8-10] and green innovation [11-13]. Involving the social aspect, some scholars further expand ecoinnovation to sustainable innovation $[14,15]$. Since there are only slight differences between these terms, researchers often use them interchangeably [16]. Eco-innovation is 
the main driver of realizing the coordinated development of the resource, environmental and economic systems and the sustainable pursuit of economic, ecological, and social benefits $[17,18]$. It is also an effective tool to transform environmental constraints into sustainable opportunities and thus enhances the comprehensive competitiveness of regions and organizations [19-21]. Due to these reasons, under the heavy pressure of the environment and resources, accelerating eco-innovation is of great value. How to enhancing eco-innovation efficiency (EIE) has thus become a focus of the government and scholars [22,23]. The 14th five-year plan issued by the Chinese government in 2020 pointed out that China should unswervingly implement the five development concepts of "innovation, coordination, green, openness, and sharing", adhere to the innovation-driven development strategy, and promote the construction of ecological civilization [24,25]. From the macroscopic, mesoscopic, and microscopic perspectives, scholars have also explored how to accelerate eco-innovation from different dimensions, such as industrial agglomeration [26], environmental regulation [27-29], regional innovation system [30], and corporate social responsibility [31]. Regarding the aspect of the industry, most studies on eco-innovation have mainly focused on the manufacturing industry for it is the most major source of environmental pollution emissions and energy consumption, and firms in the manufacturing industry have a higher eco-innovation tendency than those in other industries [32].

In China, with the continuous advancement of the industrialization process and national urban agglomeration strategy, the agglomeration feature of the manufacturing industry becomes increasingly obvious [33]. The impact of manufacturing agglomeration on EIE can no longer be ignored. A growing number of scholars have conducted related studies on the relevance between manufacturing agglomeration and EIE, but so far, scholars' views on whether manufacturing agglomeration improves the EIE have not reached a consensus. One view is that manufacturing agglomeration has negative externalities on the regional ecological environment, which are not conducive to the improvement of EIE [34]. The reason for the generation of the negative externalities is that manufacturing agglomeration will increase the concentration of enterprises in the clustering regions, and the expansion of the economic production scale of enterprises will cause more environmental pollution and energy consumption, worsening the regional ecological conditions [35]. Liu et al. [36] found that manufacturing agglomeration would intensify haze pollution. Yuan et al. [33] indicated that manufacturing agglomeration would accelerate the consumption of resources and energy.

A second view is that a reasonable manufacturing agglomeration can promote the effective play of knowledge spillover effect, scale economy effect, cooperative effect, and benign competition effect, which provide positive externalities on innovation, including eco-innovation. The positive externalities of agglomeration on eco-innovation are beneficial to the increase of EIE. Speldekamp et al. [37] indicated that industrial agglomeration facilitates the effective integration of internal and external information resources and thus enhanced the innovation potential of enterprises. Sheng et al. [38] pointed out that the agglomeration was beneficial to innovation cooperation and sharing, and improved the innovation dissemination efficiency among local cities. However, it should be noted that manufacturing agglomeration does not always have a positive impact on innovation. Hasan et al. [39] reported that the geographical proximity of enterprises would generate competition, which might offset the benefits of agglomeration. If the agglomeration is excessive, vicious competition and crowding effect will occur, and the negative externalities of agglomeration on innovation will hinder the promotion of EIE. Comprehensively considering the positive and negative externalities of agglomeration and their effects on $E I E$, based on the empirical studies on the high-end manufacturing industry of China and the manufacturing industry of Yangtze River Economic Belt of China, Li et al. [40] and Yi et al. [41] found that manufacturing agglomeration had a significant and positive impact on EIE.

In general, the above studies provide important enlightenment for the effect of manufacturing agglomeration on $E I E$, but there are still two deficiencies. First, distinguishing 
the different manufacturing agglomeration patterns has been neglected. According to whether the agglomerated enterprises in a specific area belong to the same industry sector, manufacturing agglomeration is usually separated into two patterns: one is the vertical agglomeration of enterprises among the same industry sector, that is, specialized agglomeration; the other is the horizontal agglomeration of enterprises among different industry sectors, that is, diversified agglomeration. Since knowledge has an industrial boundary and the inputs of production factors, such as labor and capital, and the market environment of agglomeration enterprises in different agglomeration patterns are different, the influence mechanism and degree of specialized and diversified agglomeration on EIE are different. An improper manufacturing agglomeration pattern will seriously restrict the improvement of EIE. Therefore, in order to effectively realize regional sustainable development, it is very urgent to clarify the impacts of specialized and diversified agglomeration on the EIE.

Second, the existing studies are mainly based on static analysis and ignore the dynamical evolution of different agglomeration patterns and the nonlinear effects of agglomeration on EIE. According to the life cycle theory of agglomeration, agglomeration is a gradual process. In different evolution stages, it has different features, which usually lie in the aspects of the allocation of resources, the establishment of shared facilities, the efficiency of research and development, and the degree of cooperation and competition between enterprises [42]. Therefore, it is very likely that the impacts of manufacturing agglomeration on EIE vary greatly in different evolution stages, that is, the relationship between manufacturing agglomeration and EIE is nonlinear. At present, few scholars have considered the dynamic characteristics of manufacturing agglomeration and conducted further studies to examine the nonlinear impacts of manufacturing agglomeration on EIE, which means whether or not a turning point exists needs to be tested.

Given the above deficiencies, this paper distinguishes the different manufacturing agglomeration patterns, studies the impacts of specialized and diversified agglomeration on EIE by using Chinese data of 21 manufacturing subindustries, and conducts a nonlinear test of their relationships from the perspective of the dynamic evolution of agglomeration. Four questions are intended to be solved: Do both manufacturing specialized agglomeration and diversified agglomeration have an impact on EIE? If so, are the influence relationships linear or nonlinear? Which kind of agglomeration pattern is superior for the improvement of EIE? Do the impacts of manufacturing specialized and diversified agglomeration on EIE have regional heterogeneity? The solutions to these problems can help the government to adjust the direction of manufacturing agglomeration, optimize the layout of the manufacturing industry, and develop regional eco-innovation strategies based on the actual situation of manufacturing agglomeration in various regions, and thus realize sustainable economic growth.

The work is organized as follows: Section 2 analyzes the theoretical framework of this study. Section 3 introduces research models and methods. Section 4 conducts several necessary model tests and describes empirical results. Section 5 makes a discussion on the results and analyzes the strengths and limitations of this study. Section 6 makes a conclusion and proposed several policy recommendations.

\section{Theoretical Framework Analysis}

According to Schumpeter's innovation theory, innovation is the establishment of a new production function, that is, a new combination of factors and production conditions that have never been introduced into the production system [43]. From this perspective, innovation can be regarded as an economic process aiming at improving efficiency and reducing costs. Innovation efficiency refers to the ratio between innovation inputs and outputs of an organization in a specific period. Different from traditional innovation, eco-innovation emphasizes not only the innovation achievements but also the reduction of adverse impacts on the environment. Therefore, EIE can be considered as the ratio relationship between various eco-innovation inputs and outputs of organizations in a specific period. The eco-innovation inputs include capital, labor, and energy, and so forth. The 
eco-innovation outputs include both desirable and undesirable outputs. According to the idea of Cobb-Douglas production function, the innovation outputs depend on innovative capital, labor, and other input factors. The function can be expressed as Formula (1) or (2) [44]:

$$
\begin{aligned}
& Y_{i t}=A_{i t}(\cdot) \cdot F(K, L) \\
& Y_{i t}=A_{i t}(\cdot) \cdot K^{\alpha_{K}} \cdot L^{\alpha_{L}}
\end{aligned}
$$

where $Y_{i t}$ is innovation output, $K$ represents capital input, $L$ denotes labor input, $A_{i t}(\cdot)$ refers to total factor productivity, $\alpha_{X}$ indicates the elasticity of each input, and $i$ and $t$ are the individual and time, respectively.

Since the input factors of eco-innovation involve energy resource input, drawing on the research of Chen et al. [45], we moderately expand and adopt the following production function forms:

$$
\begin{gathered}
Y_{i t}=A_{i t}(\cdot) \cdot F(K, L, E) \\
Y_{i t}=A_{i t}(\cdot) \cdot K^{\alpha_{K}} \cdot L^{\alpha_{L}} \cdot E^{\alpha_{E}}
\end{gathered}
$$

where, $Y_{i t}$ is eco-innovation output, including desirable and undesirable outputs, $E$ represents energy resource input, other symbols have the same meanings as those in the Formulas (1) and (2).

Manufacturing agglomeration is one of the important external factors affecting EIE [40,41]. On the one hand, it can bring together innovation capital, labor, and technology, reduce the transaction cost of eco-innovation for enterprises, and thus improve factor flow and resource allocation [46]. With these advantages, it can promote regional intensive and large-scale development, produce knowledge spillover, and improve the convenience of thinking collision and cooperation. The scale economy effect, knowledge spillover effect, cooperative effect, and benign competitive effect formed in the agglomeration process will produce positive externalities on eco-innovation $[47,48]$. On the other hand, it can also increase the concentration of enterprises. The expansion of the production scale of enterprises will cause an increase in pollutant emissions and energy consumption in the regions, generating negative externalities on eco-innovation [33,36]. Besides, as the agglomeration deepens, the number and scale of enterprises continue to increase. According to the new economic geography, when the agglomeration reaching a certain degree, subject to the limited resources, the competition among enterprises will intensify and the preemption of resources will also become fierce, leading to a crowding effect [49]. The vicious competition effect and crowding effect have negative externalities on eco-innovation.

Based on the Formula (4), manufacturing agglomeration is introduced into the above production function, and it is assumed that manufacturing agglomeration has both positive and negative externalities on the eco-innovation of a region. Then, the function is modified as follows:

$$
Y_{i t}=A_{i t}(\cdot) \cdot M A_{i t}^{\sigma} \cdot K^{\alpha_{K}} \cdot L^{\alpha_{L}} \cdot E^{\alpha_{E}}
$$

$M A$ represents regional manufacturing agglomeration effect and $M A_{i t}>0, \sigma$ is the elasticity of agglomeration. $M A_{i t}{ }^{\sigma}$ denotes that the agglomeration impacts the ecoinnovation output through both positive and negative externalities, and the symbol $\sigma$ depends on the degree of the positive and negative externalities. According to previous literature, environmental regulation, innovation capacity, industrial upgrading, and openness are vital factors influencing total factor productivity [50-52]. Therefore, $A_{i t}(\cdot)$ can be defined as follows:

$$
A_{i t}(\cdot)=G\left(E R_{i t}, I C_{i t}, I I_{i t}, O L_{i t}\right)=A_{i, 0} \cdot e^{\theta i t}
$$

where, $E R_{i t}, I C_{i t}, I I_{i t}$, and $O L_{i t}$ represent environmental regulation, innovation capacity, industrial upgrading, and openness, respectively.

Substituting Formula (6) into Formula (5) and dividing it on both sides of the equation, the equation for EIE is obtained as follows: 


$$
E I E_{i t}=\frac{Y_{i t}}{F(K, L, E)}=A_{i, 0} \cdot e^{\theta i t} \cdot M A_{i t}^{\sigma}
$$

where $E I E_{i t}$ denotes eco-innovation efficiency. Formula (7) indicates that the EIE is determined by $K, L, E$, and affected by $M A$. Taking the natural logarithm of both sides of Formula (7), the calculation formula of EIE is derived as follows:

$$
\ln E I E_{i t}=\ln A_{i, 0}+\theta_{i t}+\sigma \ln M A_{i t}+\varepsilon_{i t}
$$

Formula (8) shows that when manufacturing agglomeration forms, the agglomeration effect presents both positive and negative externalities on the eco-innovation of a region. This means that when the negative externalities of the agglomeration effect are lower than its positive externalities, the deepening of the agglomeration will improve the EIE. In contrast, when the negative externalities of the agglomeration effect are higher than its positive externalities, the agglomeration will hinder the increase of the EIE.

According to the agglomeration pattern, manufacturing agglomeration can be divided into specialized and diversified agglomeration. Owing to their differences in the factor flow and resource allocation, their influence mechanism and degree on EIE are distinctly different. For example, the former emphasizes homogeneous knowledge spillover and Mar externalities [53], while the latter emphasizes the heterogeneous knowledge spillover and Jacobs externalities [54]. These diverse externalities lead to different effects of the two agglomeration patterns on EIE. Besides, according to the life cycle theory of agglomeration, manufacturing agglomeration is a gradual process. In different agglomeration stages, factors such as the completeness of shared public facilities, the level of cooperation and competition organizations, and the efficiency of research and development vary from each other [55]. Therefore, the positive and negative externalities brought by agglomeration are dynamic and the numerical relationship between positive externalities and negative externalities are distinct in various stages, namely, whether agglomeration promotes or inhibits EIE is constantly changing. Hence, from the dynamic evolution perspective of agglomeration, the impact of manufacturing specialized and diversified agglomeration on the EIE is more likely to be nonlinear, rather than linear. The impact mechanism of manufacturing specialized and diversified agglomeration on the EIE is shown in Figure 1.

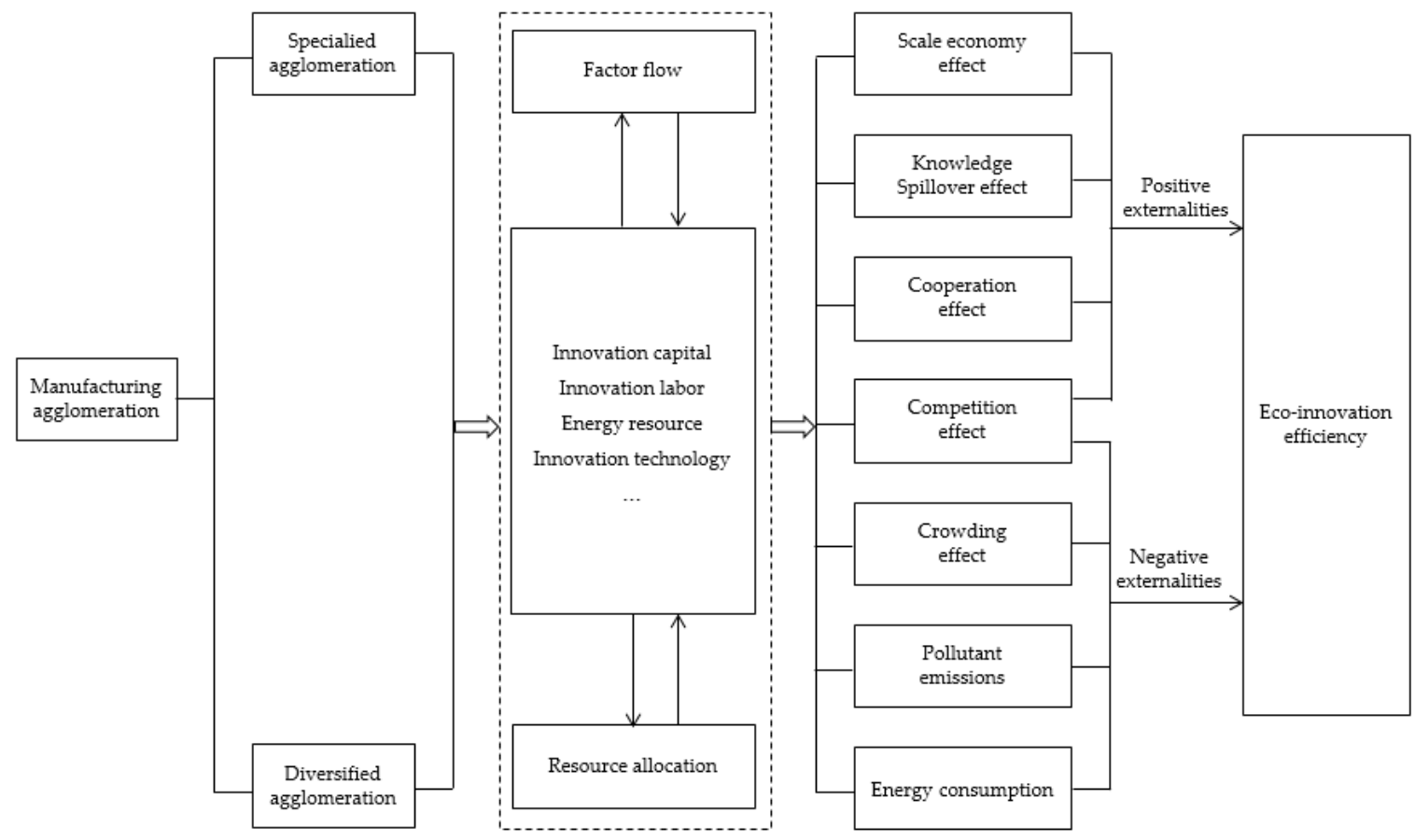

Figure 1. The impact mechanism of manufacturing specialized and diversified agglomeration on the eco-innovation efficiency (EIE). 


\section{Materials and Methods}

\subsection{The Establishment of Threshold Panel Regression Models}

The threshold panel regression model proposed by Hansen is one of the mainstream nonlinear models. It can reveal the nonlinear internal connection between various variables and provide a correct and powerful explanation for various economic phenomena. Thus, we employ the threshold panel regression model to verify whether specialized agglomeration or diversified agglomeration has a nonlinear influence on EIE.

The basic form of Hansen's threshold model is as follows [56]:

$$
\left\{\begin{array}{l}
y_{i t}=\mu_{i}+\beta_{1}{ }^{\prime} x_{i t}+\varepsilon_{i t} \text { if } q_{i t} \leq \gamma \\
y_{i t}=\mu_{i}+\beta_{2}{ }^{\prime} x_{i t}+\varepsilon_{i t} \text { if } q_{i t}>\gamma
\end{array}\right.
$$

where $y_{i t}$ is the explained variable; $x_{i t}$ is the explanatory variable; $q_{i t}$ is the threshold variable that can be part of the explanatory variable; $\gamma$ is the threshold value to be estimated; $\beta$ is the parameter to be estimated; $\mu_{i}$ denotes the features of individuals, which are not to be observed; $\varepsilon_{i t} \sim$ a.i.d. $N\left(0, \delta^{2}\right)$ is the error term; and $i$ and $t$ denote the individual and time, respectively. The model can be presented more succinctly as follows:

$$
y_{i t}=\mu_{i}+\beta_{1} x_{i t} \cdot I\left(q_{i t} \leq \gamma\right)+\beta_{2} x_{i t} \cdot I\left(q_{i t}>\gamma\right)+\varepsilon_{i t}
$$

where $I(\cdot)$ is the indicative function, i.e., when the expression in the bracket is true, its value is taken as 1 ; otherwise, its value is taken as 0 .

According to the threshold panel model, the optimal threshold should be captured so that the sum of the squares for the residuals is minimal. The threshold value $\gamma$ and the corresponding regression coefficient $\beta$ can be obtained with the nonlinear least squares method. Then, the threshold effect significance test and the threshold effect authenticity test should be implemented. For the former, Hansen uses the bootstrap to obtain the critical value of the approximate distribution, thereby obtaining the $p$-value according to the likelihood ratio test. If the $p$-value is very small, it means the null hypothesis can be significantly rejected and that a threshold effect exists. For the latter, a confidence interval is built to examine the consistency between the estimated threshold value and the real value. A simple formula is provided: $L R\left(\gamma_{0}\right) \leq \mathrm{c}(\alpha)$, where $\mathrm{c}(\alpha)=-2 \ln (1-\sqrt{1-\alpha})$ and $\alpha$ denote the significance level. The above model and formula are based on the assumption that there is only one threshold. When there are multiple thresholds, the model can be constructed in the same way. For example, the two-threshold panel model can be established as follows:

$$
y_{i t}=\mu_{i}+\beta_{1} x_{i t} \cdot I\left(q_{i t} \leq \gamma_{1}\right)+\beta_{2} x_{i t} \cdot I\left(\gamma_{1}<q_{i t} \leq \gamma_{2}\right)+\beta_{3} x_{i t} \cdot I\left(q_{i t}>\gamma_{2}\right)+\varepsilon_{i t}
$$

Among the symbols, $\gamma_{1}$ and $\gamma_{2}$ are two threshold values. Other variables have the same meanings as those in Formula (10). Owing to the length limitation, the multi-threshold threshold panel model will not be detailed here.

Based on Hansen's threshold regression model and Formula (11), we take the doublethreshold as an example and construct two threshold panel regression models. The threshold panel regression model for the effect of specialized agglomeration on EIE is Model 1:

$\ln E I E=\mu_{i}+\beta_{11} \ln S P_{i t} \cdot I\left(q_{i t} \leq \gamma_{1}\right)+\beta_{12} \ln S P_{i t} \cdot I\left(\gamma_{1}<q_{i t} \leq \gamma_{2}\right)+\beta_{13} \ln S P_{i t} \cdot I\left(q_{i t}>\gamma_{2}\right)+\beta_{1 n} X+\varepsilon_{i t}$

The threshold panel regression model for the effect of diversified agglomeration on EIE is Model 2:

$$
\ln E I E=\mu_{i}+\beta_{21} \ln D I_{i t} \cdot I\left(q_{i t} \leq \gamma_{1}\right)+\beta_{22} \ln D I_{i t} \cdot I\left(\gamma_{1}<q_{i t} \leq \gamma_{2}\right)+\beta_{23} \ln D I_{i t} \cdot I\left(q_{i t}>\gamma_{2}\right)+\beta_{2 n} X+\varepsilon_{i t}
$$

where $E I E_{i t}$ is eco-innovation efficiency; $S P_{i t}$ and $D I_{i t}$ are the specialized agglomeration degree and the diversified agglomeration degree; $I(\cdot)$ is the indicative function; $q_{i t}$ is the threshold variable; $X$ is a set of control variables impacting the EIE; $\gamma$ is the threshold value 
to be estimated; $\beta$ is the parameter to be estimated; $\mu_{i}$ denotes the features of individuals, which are not be observed; $\varepsilon_{i t}$ is the error term; and $i$ and $t$ denote the individual and time, respectively.

Besides, to study the impacts of manufacturing specialized and diversified agglomeration on the EIE more comprehensively, we incorporate these two different agglomeration patterns into a unified panel regression model. Since it is impossible to estimate a two-way threshold panel model, we look for alternative non-linear models by adding the square and cube of $\ln S P$ and $\ln D I$. Then, Models 3 and 4 are established and their results are compared with that of Models 1 and 2. Model 3 is set as follows:

$\ln E I E=\mu_{i}+\theta_{31}\left(\ln S P_{i t}\right)^{3}+\theta_{32}\left(\ln S P_{i t}\right)^{2}+\theta_{33} \ln S P_{i t}+\theta_{34} \ln \left(D I_{i t}\right)^{3}+\theta_{35} \ln \left(D I_{i t}\right)^{2}+\theta_{36} \ln D I_{i t}+\theta_{37} X+\varepsilon_{i t}$

Model 4 is set as follows:

$$
\ln E I E=\mu_{i}+\theta_{41}\left(\ln S P_{i t}\right)^{2}+\theta_{42} \ln S P_{i t}+\theta_{43} \ln \left(D I_{i t}\right)^{2}+\theta_{43} \ln D I_{i t}+\theta_{45} X+\varepsilon_{i t}
$$

where $\theta$ is the parameter to be estimated; other symbols have the same meanings as those in Formulas (12) and (13).

\subsection{The Construction of a Super-SBM Model with Undesirable Outputs}

The methods for measuring the EIE can be divided into parametric methods and nonparametric methods, which are represented by stochastic frontier analysis (SFA) and data envelope analysis (DEA), respectively. The SFA method needs to assume the distribution form of the production function beforehand, which may result in deviations in the estimated value. The DEA method can avoid that problem. It generates a frontier based on existing data without setting a given production function and can calculate the relative efficiency of a complex system. Since the evaluation of EIE is based on the complex internal structure of the eco-innovation system and the function form is unknown, scholars prefer to use data envelopment analysis (DEA) to evaluate the EIE. However, the classic DEA models such as CCR and BCC radically measure efficiency and have two disadvantages. First, they do not fully address input slack and output slack, leading to a deviation of the efficiency measurement. Second, when measuring the EIE, they ignore the undesired outputs involved in the outputs. Proposed by Tone, the slack based measure (SBM) model with undesired outputs properly solves these problems [57]. Assume that there are $n$ decision-making units (DMUs) in the eco-innovation system. $X, Y^{d}, Y^{b}$, representing inputs, desirable outputs, and undesirable outputs are three factors of a DMU. Utilizing $m$ inputs, every DMU can generate $q_{1}$ desirable outputs and $q_{2}$ undesirable outputs. Then, the SBM model with undesirable outputs is described as follows:

$$
\begin{aligned}
& \varphi=\min \frac{1-\frac{1}{m} \sum_{i=1}^{m} \frac{s_{i}^{-}}{x_{i 0}}}{1+\frac{1}{q_{1}+q_{2}}\left(\sum_{r=1}^{q_{1}} \frac{s_{r}^{d+}}{y_{r 0}^{d}}+\sum_{t=1}^{q_{2}} \frac{s_{t}^{b-}}{y_{t 0}^{b}}\right)} \\
& \text { s.t. } X \lambda+s^{-}=x_{0} \\
& Y^{d} \lambda-s_{r}^{d+}=y_{0}^{d} \\
& Y^{b} \lambda+s_{t}^{b-}=y_{0}^{b} \\
& \lambda \geq 0, s^{-} \geq 0, s^{+} \geq 0
\end{aligned}
$$

where $\varphi$ is target efficiency and $s_{i}^{-}, s^{d}$, and $s^{b}$ are the input slack, desired slack, and undesired slack, respectively. $\lambda$ is the weight vector. The efficiency values range from 0 to 1 . When the values of $s_{i}^{-}, s^{d}$, and $s^{b}$ are 0 and the value of $\varphi$ is 1 , the DMU is efficient. When $\varphi<1$, the DMU is inefficient.

In the SBM model, multiple DMUs might be efficient with a value of 1 . Having many effective DMUs is not conducive to evaluating the EIE. Therefore, based on Tone's Super-SBM model, the SBM model with undesirable outputs, and other scholars' practice, the Super-SBM model with undesirable outputs is introduced to evaluate the EIE [58]. In 
this model, the effective DMUs' efficiency values are further distinguished and can be more than 1 . We assume that technologies that can produce more desirable output and less undesirable output with the current innovation input are considered efficient, then, the output-oriented Super-SBM model with undesirable outputs is selected to assess EIE. The model is presented as follows:

$$
\begin{aligned}
& \varphi^{*}=\min \frac{1}{1-\frac{1}{q_{1}+q_{2}}\left(\sum_{r=1}^{q_{1}} \frac{s_{r}^{d+}}{y_{r k}^{d}}+\sum_{t=1}^{q_{2}} \frac{s_{t}^{b-}}{y_{t k}^{b}}\right)} \\
& \text { s.t. } \sum_{j=1, j \neq k}^{n} y_{r j}^{d} \lambda_{j}+s_{r}^{d+} \geq y_{r k}^{d} \\
& \sum_{j=1, j \neq k}^{n} y_{t j}^{b} \lambda_{j}-s_{t}^{b-} \leq y_{t k}^{b} \\
& 1-\frac{1}{q_{1}+q_{2}}\left(\sum_{r=1}^{q_{1}} s_{r}^{d+} / y_{r k}^{d}+\sum_{t=1}^{q_{2}} s_{t}^{b-} / y_{t k}^{b}\right)>0 \\
& \lambda \geq 0, s^{-} \geq 0, s^{+} \geq 0 \\
& i=1,2, \ldots, m ; j=1,2, \ldots, n(j \neq k) ; r=1,2, \ldots, q_{1} ; t=1,2, \ldots, q_{2}
\end{aligned}
$$

where $\varphi^{*}$ denotes the relative efficiency value that can be more than 1 and the other symbols are the same as those in Formula (16). When $\varphi^{*}<1$, the DMU is inefficient. When $\varphi^{*} \geq 1$, the DMU is efficient.

\subsection{Variable Selection and Data Declaration \\ 3.3.1. Dependent Variable}

The dependent variable is EIE. When calculating technical innovation efficiency, the existing studies typically take the number of patent applications or patent grants as the outputs and take the R\&D expenditure and the full-time equivalent of R\&D personnel as the inputs [59]. Compared with technology innovation, eco-innovation is reflected not only in the technological breakthroughs showed by patents but also in the realization of the coordinated development of industry and ecology through innovation. Thus, the measurement of EIE should consider not only the desirable technical outputs produced by the R\&D input costs but also the ecological costs, such as energy consumption and the undesired output of environmental pollution. Considering the data availability and objectivity, in this paper, the following indicators are used: $R \& D$ internal expenditures, the full-time equivalent of R\&D personnel, and energy consumption are taken as input indicators; the number of three kinds of domestic patents granted is taken as a desirable output indicator; and environmental pollution indicators, such as total wastewater discharge, sulfur dioxide emissions, and general industrial solid waste generation, are taken as undesirable output indicators. The Super-SBM model with undesired outputs and the software of MaxDEA 8 Ultra are used to assess EIE.

\subsubsection{Explanatory Variables}

Specialized agglomeration and diversified agglomeration are explanatory variables, which are calculated with 21 manufacturing subindustries' data. The formulas are as follows [60]:

$$
\begin{aligned}
& S P_{i t}=\max _{k t}\left(\frac{P_{i k t} / p_{i t}}{P_{k t} / P_{t}}\right) \\
& D I_{i t}=\frac{1}{\sum_{k=1}^{21}\left(\frac{P_{i k t}}{P_{i t}}-\frac{P_{k t}}{P_{t}}\right)}
\end{aligned}
$$

where $S P_{i t}$ denotes the specialized agglomeration degree in region $i$ at period $t, D I_{i t}$ denotes the diversified agglomeration degree in region $i$ at period $t, P_{i k t}$ represents the output value of industry $k$ in region $i$ at period $t, P_{i t}$ indicates the output value of all manufacturing subindustries in region $i$ at period $t, P_{k t}$ is the output value of industry $k$ in all regions 
at period $t$, and $P_{t}$ denotes the output value of all subindustries of manufacturing in all regions at period $t$. Since the classification of China's manufacturing subindustries in 2011 slightly changes, we reclassified the manufacturing industry into 21 subsectors by appropriately merging and deleting some subindustries and selected the sales output value to represent the output value. The output value of those 21 subindustries account for approximately $90 \%$ of the total output value of the manufacturing industry, thus these subindustries are sufficiently representative. The list of them is shown in Appendix A Table A1.

\subsubsection{Control Variables}

Eco-innovation is a complex process, involving interdisciplinary integration. Therefore, it is very easy for EIE to be impacted by the synthetic influence of many factors [42]. This paper chooses economic level, environmental regulation, innovation capacity, industrial upgrading, and open level as control variables.

(1) Economic level (EL)

The economic level of a region has a significant impact on EIE. First, a region with a higher economic level usually has better foundation conditions for the greening of technological innovation and higher resident needs for environmental protection. Second, since the economy in the past mainly relied on the development of traditional extensive industries, the improvement of the economic level was mostly at the expense of the ecological environment. In areas with high economic development levels, the ecological problems are relatively more serious, negatively affecting eco-innovation. The ratio of the GDP to the total population is used to measure the economic level.

(2) Environmental regulation (ER)

The assessment of EIE takes ecology into account; therefore, the relevance of ER and EIE needs to be considered. According to the Porter hypothesis, environmental regulations prompt firms to develop eco-innovation, but excessive environmental regulations may cause enterprises to face greater pressure for environmental protection and lack sufficient funds for eco-innovation. Regarding measuring the stringency of ER, because of the multidimensionality, simultaneity, industrial composition, and capital vintage, there exist many obstacles. According to the different purposes of ER, scholars use various approaches to measuring ER and all measures have several limits and drawbacks [61]. The number of environmental administrative punishment cases, the removal rate of $\mathrm{SO}_{2}$, and other emission-based environmental policy stringency indexes are common measuring methods $[33,59,60]$. Since the calculation of EIE has taken into account the energy input and pollution emissions, here we use the ratio of industrial pollution control investment to industrial added value to reflect the level of ER.

(3) Innovation capacity (IC)

Eco-innovation has a higher threshold than traditional innovation. Regions with strong innovation capabilities can provide more resources and technologies needed for eco-innovation, and their needs and willingness to carry out eco-innovation are also stronger; therefore, their EIE tends to be relatively higher [62]. The proportion of science and technology expenditure in total fiscal expenditures is used to calculate the innovation capacity.

\section{(4) Industrial upgrading (II)}

Continuously optimizing resource allocation, eliminating backward production capacity, and upgrading industrial structures are conducive to stimulating innovation vitality and enhancing the EIE. The ratio of the added value of the tertiary industry to that of the secondary industry is adopted to measure industrial upgrading. 


\section{(5) Openness (OL)}

Foreign capital investment is a manifestation of openness. According to the pollution halo hypothesis, foreign capital investment will bring cutting-edge production technologies and new operating models and promote the host country's EIE via technology spillover. However, according to the pollution paradise hypothesis, foreign capital introduced mostly belongs to polluting manufacturing industries eliminated or abandoned by the home country. This capital has a pollution transfer effect on the host country and is not conducive to its eco-innovation. Thus, it can be speculated that openness may be a double-edged sword for EIE. The proportion of foreign capital in the paid-in capital of industrial enterprises is utilized to reflect the openness.

\subsubsection{Threshold Variable}

In the threshold regression model, the explanatory variable or the independent variable can be taken as the threshold variable. Menzel and Fornahl [63] indicated that quality and quantity are two aspects reflecting the development and evolution of agglomeration. The diversity of knowledge in an agglomeration area could represent a dimension of quality, and the number of enterprises and employees in an agglomeration area could reflect a dimension of quantity. Given the complexity of quality assessment, this paper refers to the practices of other scholars and selects the dimension of quantity to evaluate the evolution stages of agglomeration [49]. Then, the enterprise scale (ES) reflected by the number of industrial enterprises above designated size is regarded as the representation of the evolution of industrial agglomeration, and the logarithm of $\mathrm{ES}(\operatorname{Ln} E S)$ is adopted as the threshold variable.

\subsubsection{Data Sources}

The data of this paper is derived from the China Statistical Yearbook of Science and Technology, the China Statistical Yearbook, the China Industry Statistical Yearbook, and the China Environmental Statistics Yearbook. Since the latest updated data of the China Industrial Statistical Yearbook is up to 2016 and much of the data on Tibet are blank, we apply the data for 30 provinces in China from 2007 to 2016 for the analysis. Macao, Taiwan, Hong Kong, and Tibet are excluded from the analysis. Table 1 shows the results of the descriptive statistics of the variables.

Table 1. Results of the descriptive statistics of variables.

\begin{tabular}{cccccc}
\hline Variable & Observations & Mean & Maximum & Minimum & Standard Deviation \\
\hline $\ln E I E$ & 300 & -0.564 & 0.200 & -1.261 & 0.299 \\
$\ln S P$ & 300 & 1.322 & 3.084 & 0.529 & 0.516 \\
$\ln D I$ & 300 & 0.543 & 1.264 & -0.107 & 0.352 \\
$\ln E L$ & 300 & 1.254 & 2.469 & -0.231 & 0.541 \\
$\ln E R$ & 300 & -5.819 & -3.574 & -7.932 & 0.725 \\
$\ln I C$ & 300 & -4.133 & -2.418 & -5.868 & 0.620 \\
$\ln I I$ & 300 & -0.098 & 1.427 & -0.699 & 0.373 \\
$\ln O L$ & 300 & -2.743 & -0.915 & -5.040 & 0.944 \\
$\ln E S$ & 300 & 1.926 & 4.182 & -1.088 & 1.215 \\
\hline
\end{tabular}

\section{Results}

\subsection{Estimation Results of EIE}

The Super-SBM model with undesired outputs is used to evaluate the EIE from 2007 to 2016. The changing trend of the EIE in the eastern, central, and western regions can be seen in Figure 2 and the specific estimated results of each province are shown in Table 2. 


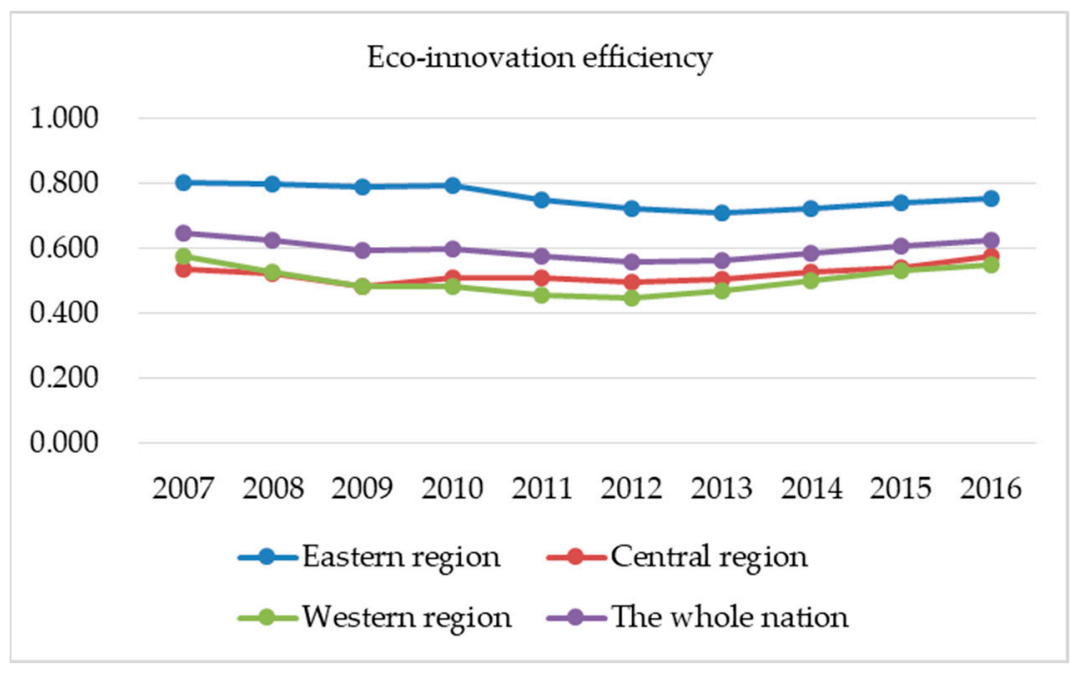

Figure 2. Mean values of the eco-innovation efficiency in eastern, central, and western regions.

Table 2. Results of the eco-innovation efficiency from 2007 to 2016.

\begin{tabular}{|c|c|c|c|c|c|c|c|c|c|c|c|}
\hline Province & 2007 & 2008 & 2009 & 2010 & 2011 & 2012 & 2013 & 2014 & 2015 & 2016 & Mean \\
\hline Eastern region & 0.800 & 0.797 & 0.787 & 0.794 & 0.749 & 0.721 & 0.709 & 0.723 & 0.738 & 0.752 & 0.757 \\
\hline Beijing & 1.207 & 1.221 & 1.204 & 1.204 & 1.150 & 1.124 & 1.152 & 1.195 & 1.201 & 1.220 & 1.188 \\
\hline Tianjin & 0.700 & 0.742 & 0.674 & 0.672 & 0.692 & 0.676 & 0.695 & 0.699 & 0.727 & 0.770 & 0.705 \\
\hline Shanghai & 1.112 & 1.086 & 1.087 & 1.096 & 0.845 & 0.763 & 0.723 & 0.739 & 0.726 & 0.764 & 0.894 \\
\hline Hebei & 0.516 & 0.482 & 0.441 & 0.456 & 0.433 & 0.420 & 0.436 & 0.467 & 0.499 & 0.520 & 0.467 \\
\hline Liaoning & 0.585 & 0.585 & 0.541 & 0.546 & 0.475 & 0.424 & 0.412 & 0.420 & 0.470 & 0.497 & 0.495 \\
\hline Jiangsu & 0.698 & 0.734 & 0.812 & 0.851 & 1.021 & 1.002 & 0.805 & 0.770 & 0.773 & 0.734 & 0.820 \\
\hline Zhejiang & 1.032 & 1.066 & 1.102 & 1.108 & 1.143 & 1.162 & 1.186 & 1.168 & 1.140 & 1.127 & 1.124 \\
\hline Fujian & 0.624 & 0.586 & 0.560 & 0.587 & 0.596 & 0.584 & 0.604 & 0.633 & 0.676 & 0.696 & 0.614 \\
\hline Shandong & 0.657 & 0.651 & 0.616 & 0.613 & 0.596 & 0.559 & 0.541 & 0.536 & 0.544 & 0.558 & 0.587 \\
\hline Guangdong & 1.054 & 1.019 & 1.021 & 1.035 & 0.806 & 0.748 & 0.750 & 0.789 & 0.816 & 0.848 & 0.889 \\
\hline Hainan & 0.615 & 0.598 & 0.599 & 0.561 & 0.487 & 0.471 & 0.498 & 0.533 & 0.550 & 0.537 & 0.545 \\
\hline Central region & 0.537 & 0.523 & 0.483 & 0.506 & 0.508 & 0.495 & 0.504 & 0.525 & 0.541 & 0.576 & 0.520 \\
\hline Anhui & 0.504 & 0.494 & 0.525 & 0.590 & 0.643 & 0.621 & 0.621 & 0.629 & 0.624 & 0.641 & 0.589 \\
\hline Jiangxi & 0.458 & 0.427 & 0.388 & 0.407 & 0.435 & 0.437 & 0.455 & 0.519 & 0.564 & 0.598 & 0.469 \\
\hline Heilongjiang & 0.603 & 0.576 & 0.524 & 0.504 & 0.551 & 0.574 & 0.562 & 0.545 & 0.555 & 0.568 & 0.556 \\
\hline Henan & 0.549 & 0.555 & 0.497 & 0.503 & 0.491 & 0.485 & 0.487 & 0.518 & 0.544 & 0.564 & 0.519 \\
\hline Hubei & 0.579 & 0.571 & 0.536 & 0.551 & 0.496 & 0.472 & 0.486 & 0.494 & 0.517 & 0.555 & 0.526 \\
\hline Hunan & 0.574 & 0.530 & 0.484 & 0.522 & 0.501 & 0.495 & 0.489 & 0.521 & 0.525 & 0.537 & 0.518 \\
\hline Jilin & 0.557 & 0.537 & 0.441 & 0.457 & 0.442 & 0.403 & 0.405 & 0.434 & 0.449 & 0.508 & 0.463 \\
\hline Shanxi & 0.473 & 0.495 & 0.472 & 0.517 & 0.501 & 0.473 & 0.523 & 0.536 & 0.551 & 0.640 & 0.518 \\
\hline Western region & 0.574 & 0.524 & 0.483 & 0.480 & 0.455 & 0.445 & 0.470 & 0.499 & 0.530 & 0.548 & 0.501 \\
\hline Gansu & 0.482 & 0.441 & 0.398 & 0.424 & 0.412 & 0.417 & 0.453 & 0.473 & 0.493 & 0.534 & 0.453 \\
\hline Guangxi & 0.532 & 0.498 & 0.436 & 0.415 & 0.421 & 0.407 & 0.450 & 0.503 & 0.540 & 0.562 & 0.476 \\
\hline Guizhou & 0.627 & 0.599 & 0.536 & 0.552 & 0.504 & 0.536 & 0.559 & 0.585 & 0.596 & 0.568 & 0.566 \\
\hline Inner Mongolia & 0.501 & 0.437 & 0.335 & 0.327 & 0.296 & 0.287 & 0.310 & 0.342 & 0.360 & 0.387 & 0.358 \\
\hline Ningxia & 0.427 & 0.528 & 0.505 & 0.491 & 0.361 & 0.354 & 0.403 & 0.439 & 0.456 & 0.513 & 0.448 \\
\hline Qinghai & 0.496 & 0.487 & 0.420 & 0.284 & 0.378 & 0.331 & 0.323 & 0.383 & 0.503 & 0.513 & 0.412 \\
\hline Shaanxi & 0.473 & 0.495 & 0.472 & 0.517 & 0.501 & 0.473 & 0.523 & 0.536 & 0.551 & 0.640 & 0.518 \\
\hline Sichuan & 0.595 & 0.616 & 0.613 & 0.637 & 0.573 & 0.577 & 0.574 & 0.585 & 0.605 & 0.597 & 0.597 \\
\hline Chongqing & 0.614 & 0.576 & 0.570 & 0.620 & 0.608 & 0.590 & 0.606 & 0.614 & 0.653 & 0.655 & 0.611 \\
\hline Xinjiang & 1.006 & 0.563 & 0.516 & 0.511 & 0.479 & 0.460 & 0.503 & 0.522 & 0.564 & 0.550 & 0.567 \\
\hline Yunnan & 0.563 & 0.524 & 0.513 & 0.507 & 0.469 & 0.460 & 0.469 & 0.511 & 0.514 & 0.514 & 0.505 \\
\hline Mean & 0.647 & 0.622 & 0.593 & 0.599 & 0.573 & 0.557 & 0.563 & 0.585 & 0.607 & 0.625 & 0.597 \\
\hline
\end{tabular}


From the perspective of the whole nation, the EIE of China generally shows a Ushaped trend. From 2007 to 2012, the EIE dropped from 0.647 to 0.557. China's traditional economic development was mostly based on extensive manufacturing. During this period, green development was ignored in China, causing serious damage to resources and the ecological environment and resulting in a decrease in EIE. With the depletion of energy and the intensification of environmental pollution, eco-innovation gradually became the main focus of the government for its role in promoting industrial upgrading. A series of related policies and measures were proposed and implemented. For example, the 18th National Congress of the Communist Party of China in 2012 proposed to implement the innovation-driven development strategy, transforming the development path from factordriven development to innovation-driven development. The Made in China 2025 plan issued in 2015 and the 13th five-year plan from 2016 to 2020 both regarded ecological civilization construction and green innovation as main components or included guidelines focusing on these concepts. These measures worked. The EIE increased year by year and reached 0.625 in 2016.

From the perspective of different regions, the EIE is regionally heterogeneous. In the eastern region, the EIE is relatively high, with an average value of 0.757 . In particular, the EIE in Beijing and Zhejiang is even more than 1.000, indicating that the DMUs are sufficiently effective. In the central and western regions, the mean value of EIE is only approximately 0.5 , which is slightly low. This phenomenon generally conforms to the spatial layout of Chinese industries in recent years. As the first-pilot areas for the reform and opening-up policies, the cities and provinces in the east have long been gathering places for production factors, such as talent, capital, and technologies. The industries gathered in these areas are mostly technology-intensive industries with higher innovation outputs and relatively lower pollution, and thus their EIE is far ahead. However, in the central and western regions, the industries are generally labor-intensive and capital-intensive ones with lower innovation outputs and higher pollution. Meanwhile, under the national policy by which industries began shifting from east to west in China, the central and western regions have vigorously undertaken the establishment of some low-end industries based on their advantages of resource-based endowment, low-cost factors, and large market potential, which has further widened the EIE gap between these regions and the areas in the east.

\subsection{Model Stational Test}

\subsubsection{Panel Data Unit Root Test}

To avoid the existence of spurious regression, the stationarity of the data series should be tested before the parameter estimation of Models 1 to 4 . The most commonly used method is the unit root test, which mainly includes augmented Dickey-Fuller (ADF)-Fisher test, Phillips-Perron (PP)-Fisher test, Levin-Lin-Chu (LLC) test, and Im-Pesaran-Shin (IPS) test. The LLC test, IPS test, and ADF-Fisher test are chosen in this paper to examine the stationarity of $\ln E I E,(\ln S P)^{3},(\ln S P)^{2}, \ln S P,(\ln D I)^{3},(\ln D I)^{2}, \ln D I, \ln E L, \ln E R, \ln I C, \ln I I$, $\ln O L, \ln E S$, respectively. The results in Table 3 indicate that several data series accept the null hypothesis with a unit root at a significance level of $5 \%$ but all series after first-order difference processing reject that null hypothesis at a significance level of $5 \%$. Therefore, all the variables in Models 1 to 4 are first-order single-integrated and further cointegration tests are needed to analyze whether the variables have long-term stable proportional relationships. 
Table 3. Unit root test results of all variables.

\begin{tabular}{|c|c|c|c|}
\hline Variable & LLC Test & IPS Test & ADF-Fisher Test \\
\hline $\ln E I E$ & $-9.2157^{* * *}$ & 1.9480 & 0.8415 \\
\hline$\Delta \ln E I E$ & $-15.0792^{* * *}$ & $-5.6447^{* * *}$ & $13.7697 * * *$ \\
\hline$(\ln S P)^{3}$ & $-7.2847^{* * *}$ & 2.7924 & -0.3823 \\
\hline$\Delta(\ln S P)^{3}$ & $-5.8667^{* * *}$ & $-2.9240^{* * *}$ & $-6.4180^{* * *}$ \\
\hline$(\ln S P)^{2}$ & $-6.1064^{* * *}$ & 2.7321 & $5.4535^{* * *}$ \\
\hline$\Delta(\ln S P)^{2}$ & $-5.3708^{* * *}$ & $-2.8952 * * *$ & $-5.2053^{* * *}$ \\
\hline $\ln S P$ & $-6.1759 * * *$ & 1.2769 & -2.4690 \\
\hline$\Delta \ln S P$ & $-12.4964^{* * *}$ & $-5.0130 * * *$ & $11.3777^{* * *}$ \\
\hline$(\ln D I)^{3}$ & $-1.9200^{* *}$ & 3.6440 & 3.3143 \\
\hline$\Delta(\ln D I)^{3}$ & $-5.1913^{* * *}$ & $-4.2192 * * *$ & $-7.6814^{* * *}$ \\
\hline$(\ln D I)^{2}$ & -1.0621 & 3.0772 & 2.9010 \\
\hline$\Delta(\ln D I)^{2}$ & $-5.3707^{* * *}$ & $-4.1405^{* *}$ & $-7.6752 * * *$ \\
\hline $\ln D I$ & $-5.7538^{* * *}$ & -1.0734 & $4.9061^{* * *}$ \\
\hline$\Delta \ln D I$ & $-21.8736^{* * *}$ & $-5.2585^{* * *}$ & $13.0067^{* * *}$ \\
\hline $\ln E L$ & 1.4785 & 5.4155 & -5.0006 \\
\hline$\Delta \ln E L$ & $-25.6450^{* * *}$ & $-5.0068^{* * *}$ & $2.3017^{* *}$ \\
\hline $\ln E R$ & $-8.7228^{* * *}$ & $-2.0862 * *$ & 0.9287 \\
\hline$\Delta \ln E R$ & $-5.5414^{* * *}$ & $-4.8355^{* * *}$ & $14.4568^{* * *}$ \\
\hline $\ln I C$ & $-1.6267^{*}$ & $-5.6971^{* * *}$ & $60.0999 * * *$ \\
\hline$\Delta \ln I C$ & $-12.0718^{* * *}$ & $-6.2074^{* * *}$ & $68.8012 * * *$ \\
\hline $\ln I I$ & $1.0504^{* * *}$ & 2.8250 & -4.9863 \\
\hline$\Delta \ln I I$ & $-34.0508^{* * *}$ & $-5.8542^{* * *}$ & $10.4315^{* * *}$ \\
\hline $\ln O L$ & $-5.5788^{* * *}$ & $-4.2549^{* * *}$ & 0.3140 \\
\hline$\Delta \ln O L$ & $-8.2943^{* * *}$ & $-5.8338^{* * *}$ & $31.2244^{* * *}$ \\
\hline $\ln E S$ & $-6.5519 * * *$ & $-5.0146^{* * *}$ & $9.1756^{* * *}$ \\
\hline$\Delta \ln E S$ & $-7.4911^{* * *}$ & $-5.8855^{* * *}$ & $23.4938^{* * *}$ \\
\hline
\end{tabular}

Notes: ${ }^{*} p<0.1,{ }^{* *} p<0.05,{ }^{* * *} p<0.01 ; \Delta$ represents the first difference; the results of Levin-Lin-Chu (LLC) Im-Pesaran-Shin (IPS), and augmented Dickey-Fuller (ADF)-Fisher tests correspond to the statistic values of adjusted $t^{*}, \mathrm{z}$-t-tilde-bar, and inverse normal $\mathrm{z}$, respectively.

\subsubsection{Cointegration Test}

Kao test is a commonly used cointegration test method. The test results of Models 1 to 4 are shown in Table 4 . It can be seen that the Kao tests all reject the null hypothesis that there is no cointegration relationship between variables at a significance level of $1 \%$. Therefore, there is a cointegration relationship among the variables in every model, and regression analysis can be conducted.

Table 4. Cointegration test results of the variables in Models 1 to 4.

\begin{tabular}{ccccc}
\hline Model & Testing Method & Statistic & Statistic Value & $p$-Value \\
\hline Model 1 & & $-2.3316^{* * *}$ & 0.0099 \\
Model 2 & Kao test & ADF t & $-2.6503^{* * *}$ & 0.0040 \\
Model 3 & & $-2.9284^{* * *}$ & 0.0017 \\
Model 4 & & $-2.9239^{* * *}$ & 0.0017 \\
\hline
\end{tabular}

Notes: ${ }^{* * *} p<0.01$.

\subsection{Selection of Panel Data Model}

Since the panel data has two-dimensional characteristics of time series and crosssection, it is necessary to select a setting form of the model before parameter estimation to avoid large deviations of the estimated results caused by the unreasonable model form. The forms of the panel data model include pooled regression model (PR), fixed effects regression model (FE), and random effects regression model (RE). The F test, LM test, and Hausman test are used to determine which setting form should be adopted for the panel data models in this paper. From the results in Table 5, it can be seen that the $p$ values of the $\mathrm{F}$ test are 0.0000 , indicating that the FE is significantly better than the PR; The $p$ values of 
the LM test are 0.0000 , showing that the RE is significantly better than the PR; and the $p$ values of Hausman test are 0.0000, reflecting that the FE is significantly better than the RE. Therefore, the form of FE should be used for Models 1 to 4 .

Table 5. Selection of setting form of Models 1 to 4 .

\begin{tabular}{|c|c|c|c|c|c|c|}
\hline Model & $\begin{array}{l}\text { Testing } \\
\text { Method }\end{array}$ & Statistic & Statistic Value & $p$-Value & Conclusion & $\begin{array}{l}\text { Model Setting } \\
\text { Form }\end{array}$ \\
\hline \multirow{3}{*}{ Model 1} & F test & F & $16.64^{* * *}$ & 0.0000 & FE is significantly better than PR & \multirow{3}{*}{$\mathrm{FE}$} \\
\hline & LM test & Chibar2 & $177.54^{* * *}$ & 0.0000 & $\mathrm{RE}$ is significantly better than PR & \\
\hline & Hausman test & Chi2 & $67.97^{* * *}$ & 0.0000 & FE is significantly better than RE & \\
\hline \multirow{3}{*}{ Model 2} & F test & $\mathrm{F}$ & $18.39^{* * *}$ & 0.0000 & FE is significantly better than PR & \multirow{3}{*}{$\mathrm{FE}$} \\
\hline & LM test & Chibar2 & $247.03^{* * *}$ & 0.0000 & $\mathrm{RE}$ is significantly better than PR & \\
\hline & Hausman test & Chi2 & $58.83^{* * *}$ & 0.0000 & FE is significantly better than RE & \\
\hline \multirow{3}{*}{ Model 3} & F test & $\mathrm{F}$ & $6.55^{* * *}$ & 0.0000 & FE is significantly better than PR & \multirow{3}{*}{$\mathrm{FE}$} \\
\hline & LM test & Chibar2 & $134.11^{* * *}$ & 0.0000 & $\mathrm{RE}$ is significantly better than PR & \\
\hline & Hausman test & Chi2 & $74.43^{* * *}$ & 0.0000 & FE is significantly better than RE & \\
\hline \multirow{3}{*}{ Model 4} & F test & $\mathrm{F}$ & $7.56^{* * *}$ & 0.0000 & FE is significantly better than PR & \multirow{3}{*}{$\mathrm{FE}$} \\
\hline & LM test & Chibar2 & $130.54^{* * *}$ & 0.0000 & $\mathrm{RE}$ is significantly better than PR & \\
\hline & Hausman test & Chi2 & $78.99 * * *$ & 0.0000 & FE is significantly better than RE & \\
\hline
\end{tabular}

\subsection{Threshold Effect Test}

\subsubsection{Threshold Effect Significance Test}

Using $\ln E S$ as a threshold variable, a threshold effect significance test at a $95 \%$ confidence interval is conducted. Table 6 shows that the three-threshold tests in both Models 1 and 2 pass the significance tests and that the threshold values of $\ln E S$ are $-0.589,0.551$, and 2.297 in Model 1, and -0.145, 2.297, and 3.171 in Model 2.

Table 6. Threshold effect and test results.

\begin{tabular}{|c|c|c|c|c|c|c|c|c|c|}
\hline Model & $\begin{array}{l}\text { Threshold } \\
\text { Variable }\end{array}$ & $\begin{array}{c}\text { Threshold } \\
\text { Model }\end{array}$ & F-Value & $p$-Value & $1 \%$ & $5 \%$ & $10 \%$ & $\begin{array}{l}\text { Threshold } \\
\text { Estimates }\end{array}$ & $\begin{array}{c}95 \% \\
\text { Confidence } \\
\text { Interval }\end{array}$ \\
\hline \multirow{3}{*}{ Model 1} & \multirow{3}{*}{$\ln E S$} & Single-threshold & $24.651^{* * *}$ & 0.004 & 16.754 & 9.180 & 6.718 & 2.297 & {$[2.280,2.386]$} \\
\hline & & $\begin{array}{l}\text { Double- } \\
\text { threshold }\end{array}$ & $9.971 *$ & 0.052 & 21.432 & 10.298 & 6.587 & $\begin{array}{l}0.551 \\
2.297\end{array}$ & {$[-0.553,0.553]$} \\
\hline & & Three-threshold & $8.449^{* *}$ & 0.042 & 10.526 & 8.208 & 6.708 & -0.589 & {$[-0.589,3.955]$} \\
\hline \multirow{3}{*}{ Model 2} & \multirow{3}{*}{$\ln E S$} & Single-threshold & $14.254^{* *}$ & 0.022 & 17.902 & 7.045 & 3.891 & -0.125 & {$[-0.705,3.744]$} \\
\hline & & Double- & $-1.808 *$ & 0.092 & 7.107 & 1.940 & -2.418 & 3.171 & {$[-0.551,3.744]$} \\
\hline & & $\begin{array}{l}\text { threshold } \\
\text { Three-threshold }\end{array}$ & $7.771^{* *}$ & 0.024 & 11.922 & 5.645 & 3.442 & $\begin{array}{l}2.297 \\
-0.145\end{array}$ & {$[-0.717,3.753]$} \\
\hline
\end{tabular}

Notes: ${ }^{*} p<0.1,{ }^{* *} p<0.05,{ }^{* * *} p<0.01 ;$ Bootstrap $=500 ;$ Minobs $=10$.

\subsubsection{Threshold Effect Authenticity Test}

The likelihood ratio test statistic, LR, is adopted to examine the authenticity of the thresholds values. Figures 3 and 4 are the LR graphs for the threshold estimate of $\ln E S$ in Models 1 and 2 at the significance level of $5 \%$. The LR values in Models 1 and 2 are all less than 7.35; thus, the threshold values pass the authenticity test. 


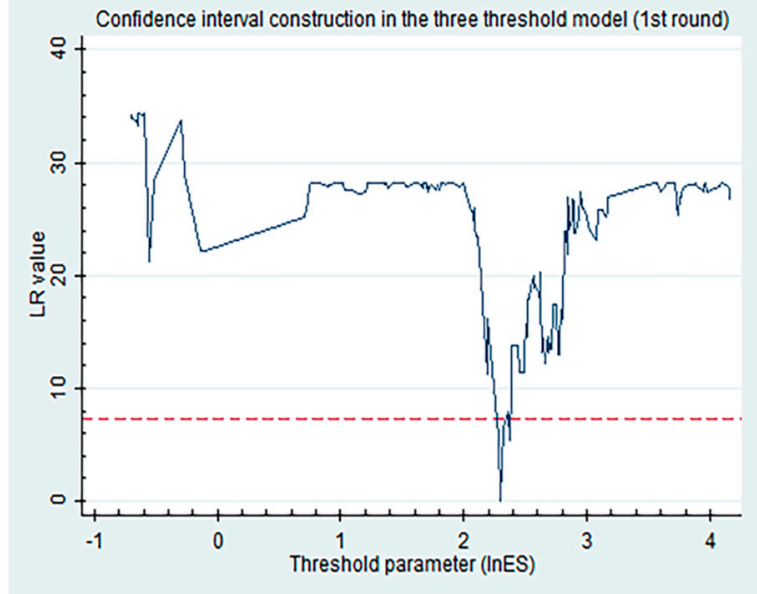

(a)



(b)

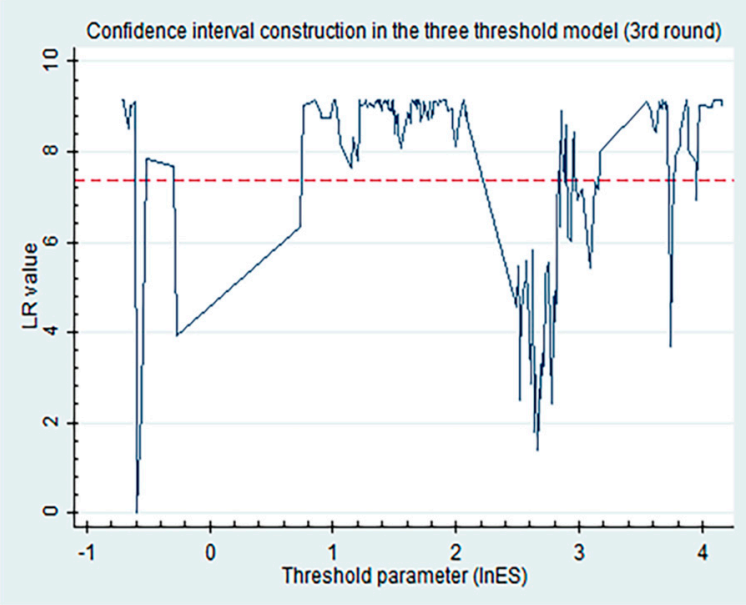

(c)

Figure 3. The likelihood ratio (LR) graphs for the threshold estimate of $\ln E S$ in Model 1. (a) The first threshold estimate; (b) the second threshold estimate; (c) the third threshold estimate.

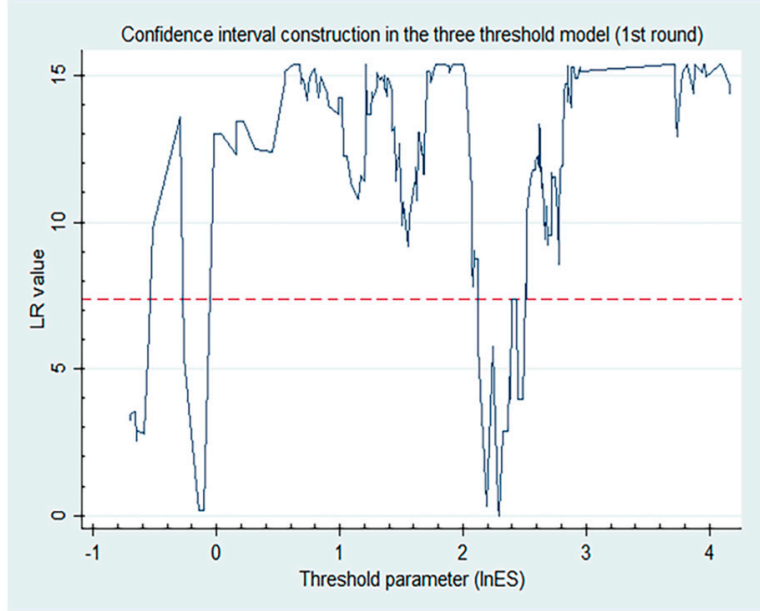

(a)



(b)

Figure 4. Cont. 


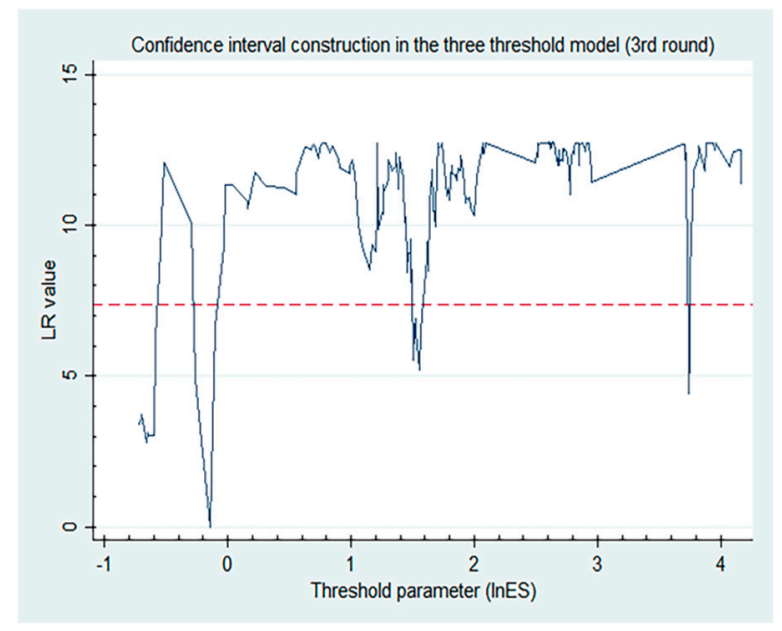

(c)

Figure 4. The LR graphs for the threshold estimate of $\ln E S$ in Model 2. (a)The first threshold estimate; (b) the second threshold estimate; $(\mathbf{c})$ the third threshold estimate.

\subsection{Estimation Results and Analysis}

4.5.1. Impacts of Specialized and Diversified Agglomeration on EIE at the National Level

The threshold effect tests verify that at the significance level of $5 \%$, the impacts of specialized and diversified agglomeration on EIE are nonlinear and both have threethreshold effects. Therefore, it is appropriate to adopt the panel three-threshold regression model to estimate the impacts of specialized and diversified agglomeration on EIE. The results are shown in Table 7.

Table 7. Results of impacts of specialized and diversified agglomeration on EIE.

\begin{tabular}{|c|c|c|c|c|c|c|c|}
\hline Variable & Model 1 & Variable & Model 2 & Variable & Model 3 & Variable & Model 4 \\
\hline $\begin{array}{c}\ln S P(\ln E S \leq \\
-0.589)\end{array}$ & $\begin{array}{l}-0.071 \\
(-1.07)\end{array}$ & $\begin{array}{c}\ln D I(\ln E S \leq \\
-0.145)\end{array}$ & $\begin{array}{l}-0.315 \\
(-1.37)\end{array}$ & $\ln (S P)^{3}$ & $\begin{array}{l}0.073 \\
(0.97)\end{array}$ & $\ln (S P)^{2}$ & $\begin{array}{l}0.003 \\
(0.05)\end{array}$ \\
\hline $\begin{array}{l}\ln S P(-0.589< \\
\ln E S \leq 0.551)\end{array}$ & $\begin{array}{l}0.025 \\
(0.42)\end{array}$ & $\begin{array}{l}\ln D I(-0.145< \\
\ln E S \leq 2.297)\end{array}$ & $\begin{array}{l}0.278^{* * *} \\
(3.07)\end{array}$ & $\ln (S P)^{2}$ & $\begin{array}{l}-0.344 \\
(-1.01)\end{array}$ & $\ln S P$ & $\begin{array}{l}0.015 \\
(0.07)\end{array}$ \\
\hline $\begin{array}{c}\ln S P(0.551<\ln E S \\
\leq 2.297)\end{array}$ & $\begin{array}{l}-0.084^{*} \\
(-1.69)\end{array}$ & $\begin{array}{c}\ln D I(2.297<\ln E S \\
\leq 3.171)\end{array}$ & $\begin{array}{c}0.434^{* * *} \\
(5.13)\end{array}$ & $\ln S P$ & $\begin{array}{l}0.534 \\
(1.07)\end{array}$ & $\ln (D I)^{2}$ & $\begin{array}{l}0.233 * \\
(1.96)\end{array}$ \\
\hline $\ln S P(\ln E S \geq 2.297)$ & $\begin{array}{l}0.135^{*} \\
(1.96)\end{array}$ & $\ln D I(\ln E S \geq 3.171)$ & $\begin{array}{l}0.426^{* * *} \\
(3.03)\end{array}$ & $\ln (D I)^{3}$ & $\begin{array}{l}-0.452 * \\
(-1.73)\end{array}$ & $\ln D I$ & $\begin{array}{l}0.083 \\
(0.45)\end{array}$ \\
\hline $\ln E L$ & $\begin{array}{l}-0.131^{* * *} \\
(-5.59)\end{array}$ & $\ln E L$ & $\begin{array}{l}-0.169^{* * *} \\
(-6.47)\end{array}$ & $\ln (D I)^{2}$ & $\begin{array}{l}1.048^{* *} \\
(2.20)\end{array}$ & $\ln E L$ & $\begin{array}{c}-0.166^{* * *} \\
(-6.17)\end{array}$ \\
\hline $\ln E R$ & $\begin{array}{l}-0.001 \\
(-0.07)\end{array}$ & $\ln E R$ & $\begin{array}{c}-0.009 \\
(0.72)\end{array}$ & $\ln D I$ & $\begin{array}{l}-0.261 \\
(-0.99)\end{array}$ & $\ln E R$ & $\begin{array}{l}0.006 \\
(0.43)\end{array}$ \\
\hline $\ln I C$ & $\begin{array}{l}0.054^{* *} \\
(2.52)\end{array}$ & $\ln I C$ & $\begin{array}{l}0.078^{* * * *} \\
(3.64)\end{array}$ & $\ln E L$ & $\begin{array}{l}-0.163 \text { ** } \\
(-6.00)\end{array}$ & $\ln I C$ & $\begin{array}{l}0.084^{* * *} \\
(3.95)\end{array}$ \\
\hline $\ln I I$ & $\begin{array}{l}0.194^{* * *} \\
(4.33)\end{array}$ & $\ln I I$ & $\begin{array}{c}0.180^{* * *} \\
(4.12)\end{array}$ & $\ln E R$ & $\begin{array}{l}0.007 \\
(0.54)\end{array}$ & $\ln I I$ & $\begin{array}{l}0.151^{* * *} \\
(3.27)\end{array}$ \\
\hline $\ln O L$ & $\begin{array}{l}-0.062 * * \\
(-2.31)\end{array}$ & $\ln O L$ & $\begin{array}{c}-0.078^{* * *} \\
(-2.82)\end{array}$ & $\ln I C$ & $\begin{array}{c}0.091^{* * *} \\
(4.24)\end{array}$ & $\ln O L$ & $\begin{array}{l}-0.091^{* * * *} \\
(-3.23)\end{array}$ \\
\hline \multirow[t]{3}{*}{ Constant } & $\begin{array}{l}-0.327^{* *} \\
(-2.17)\end{array}$ & Constant & $\begin{array}{l}-0.377^{* * * *} \\
(-2.84)\end{array}$ & $\ln I I$ & $\begin{array}{c}0.153^{* * *} \\
(3.33)\end{array}$ & Constant & $\begin{array}{l}-0.379 * \\
(-1.75)\end{array}$ \\
\hline & & & & $\ln O L$ & $\begin{array}{l}-0.087^{* * * *} \\
(-3.11)\end{array}$ & & \\
\hline & & & & Constant & $\begin{array}{l}-0.569^{* *} \\
(-2.06)\end{array}$ & & \\
\hline
\end{tabular}


According to the results of Model 1, there are three turning points: a turning point occurs when the ES reaches 555 enterprises $\left(\ln E S=-0.589, \mathrm{ES}=\mathrm{e}^{-0.589}=0.555\right.$ thousand enterprises, the same below), 1735 enterprises, and 9944 enterprises, respectively. When the ES is lower than 1735 enterprises, at the significant level of 10\%, the impact of specialized agglomeration on EIE is not significant. When the ES is more than 1735 enterprises but less than 9944 enterprises, at the significance level of $10 \%$, the specialized agglomeration is not conducive to the EIE, with an influence coefficient of -0.084 . Once the ES exceeds 9944 enterprises, the impact of specialized agglomeration on EIE turns to be positive, and the influence coefficient changes to 0.135 . In general, the relationship between specialized agglomeration and EIE is U-shaped, indicating that the agglomeration will first inhibit and then promote the increase of EIE. This conclusion is consistent with the viewpoints of Claver-Cortés et al. [64], indicating that specialized agglomeration had both positive and negative impacts on the innovation of local enterprises.

As for the results of Model 2, there are also three turning points: a turning point occurs when the ES reaches 1156 enterprises, 9944 enterprises, and 23,831 enterprises, respectively. When the ES is less than 1156 enterprises, the impact of diversified agglomeration on EIE is not significant. When the ES exceeds 1156 enterprises, diversity agglomeration begins to significantly promote EIE, with an influence coefficient of 0.278 . When the ES reaches 9944 enterprises, the influence coefficient increases to 0.434 . However, as the ES continues to expand to 23,831 enterprises, the influence coefficient drops slightly to 0.426 . Namely, there is an S-shaped relationship between diversified agglomeration and EIE. As long as the ES surpasses 1156 enterprises, diversified agglomeration will stimulate the increase of EIE and the promoting effect will increase first and then decrease. This outcome supports the viewpoints of Meili and Shearmur [65] and Lee and Sohh [66], indicating that diversified agglomeration could positively affect innovation, while it is very different from the finding of Zeng et al. [26], showing that industrial collaborative agglomeration has a U-shaped impact on green innovation (eco-innovation).

In Models 3 and 4, two different agglomeration patterns are incorporated into a unified panel regression model. The results of Model 3 show that at the significance level of $5 \%$ and $10 \%$ respectively, the impacts of $(\ln D I)^{2}$ and $(\ln D I)^{3}$ on $\ln E I E$ are significant. The results of Model 4 show that at the significance level of $10 \%$, the impact of $(\ln D I)^{2}$ on $\ln E I E$ is significant. These results further support that there is a significant nonlinear relationship between diversified agglomeration and EIE, which is similar to the conclusion of Model 2. However, regardless of the Model 3 or the Model 4, at the significance level of $10 \%$, the effects of $\ln S P,(\ln S P)^{2}$, and $(\ln S P)^{3}$ on $\ln E I E$ are not significant, which are very different from the result of Model 1. The differences might be attribute to the threshold effects and the regional heterogeneity in the relationship between specialized agglomeration and the EIE. When the enterprise scale is in different intervals, the impact of specialized agglomeration on EIE is sometimes positive in some regions and sometimes negative in other regions, the offset effect leads to specialized agglomeration's insignificant impact on EIE. Thus, to further analyze the different impacts of manufacturing specialized and diversified agglomeration on EIE in different regions is of great necessity.

Regarding the control variables, at the significance level of $1 \%$ or $5 \%$, the coefficients of innovation capacity and industrial upgrading are significantly positive, suggesting that the innovation capacity and the industrial upgrading are beneficial to improve EIE. At the significance level of $1 \%$, the coefficients of the economic level are significantly negative. This is because of the extensive production methods developing the economy at the expense of ecology in the past. Ecological problems in regions with higher levels of economic development are relatively more serious, which is not good for the promotion of EIE. At the significance level of $1 \%$ or $5 \%$, the openness is not conducive to EIE, showing that there exists the pollution paradise hypothesis in China. At the significance level of $10 \%$, the coefficients of ER are insignificant, revealing that ER has an insignificant impact on EIE. To avoid that the insignificant results are caused by an inappropriate measure of the ER, learning from the study of Brunel and Levinson, we use the indicator of the reciprocal 
of emission intensity to quantitatively assess the ER again [61]. Specifically, the indicator is determined by dividing the industrial added value by the total amount of $\mathrm{SO}_{2}$ emissions in the region. The higher the values are, the more stringent the environmental regulations in the regions are. Then, we repeat all the econometric analysis, results show that at the significance level of $10 \%$, the coefficients of ER in Models 1 to 4 are still insignificant, which are consistent with the previous results. Given the length limitation of the paper, the specific results are omitted here. As for why the effect of ER on EIE is not significant, one possible reason is that ER may be a double-edged sword for EIE. For example, although strict environmental regulations can stimulate enterprises' eco-innovation, they will also increase the production and environmental protection costs of enterprises, which in turn restrict their investment in eco-innovation technologies.

\subsubsection{Impacts of Specialized and Diversified Agglomeration on EIE at the Regional Level}

To further explore the impacts of manufacturing specialized and diversified agglomeration on EIE in different regions, this paper selects data for 2007 and 2016 of 30 provinces in China as a sample and analyzes the regional distribution of the ES relative to the threshold values. The results can be seen in Figures 5 and 6.

Regarding the regional distribution of ES in 2016, the specialized agglomeration has a positive impact on EIE in $40 \%$ of the provinces and a negative impact on EIE in $50 \%$ of the provinces. Diversified agglomeration has a positive impact on EIE in more than $90 \%$ of the provinces. These proportions reflect the fact that in terms of eco-innovation, the development of diversified agglomeration is superior to that of specialized agglomeration. According to the regression results of Models 1 and 2, the range of [9944, 23831] is the relative optimal range of ES, within which the comprehensive positive impact of specialized and diversified agglomeration on EIE is greatest. As for the comprehensive impact of specialized and diversified agglomeration on EIE, the percentage of provinces having an ES within that range has increased by 3\% from 2007 to 2016; thus, the overall regional distribution of ES in China has been slightly optimized.

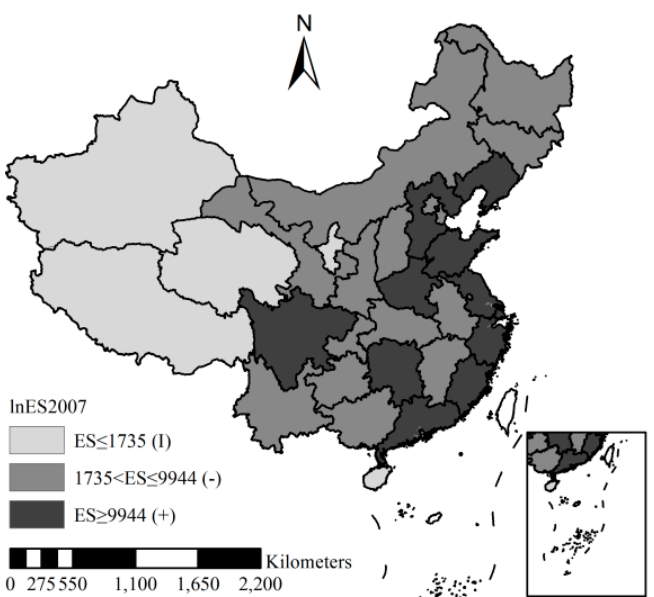

(a)

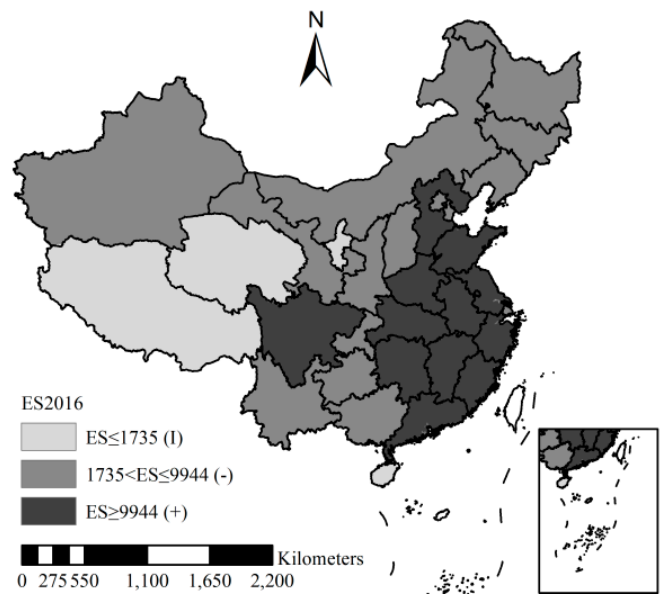

(b)

Figure 5. The regional distribution of the enterprise scale (ES) relative to the impact of specialized agglomeration on EIE. (a) The regional distribution of the ES in 2007; (b) the regional distribution of the ES in 2016. Figures in parentheses represent the impact of specialized agglomeration on EIE. "I" represents that the impact is insignificant; "-"represents that the impact is negative; "+" represents that the impact is positive. 


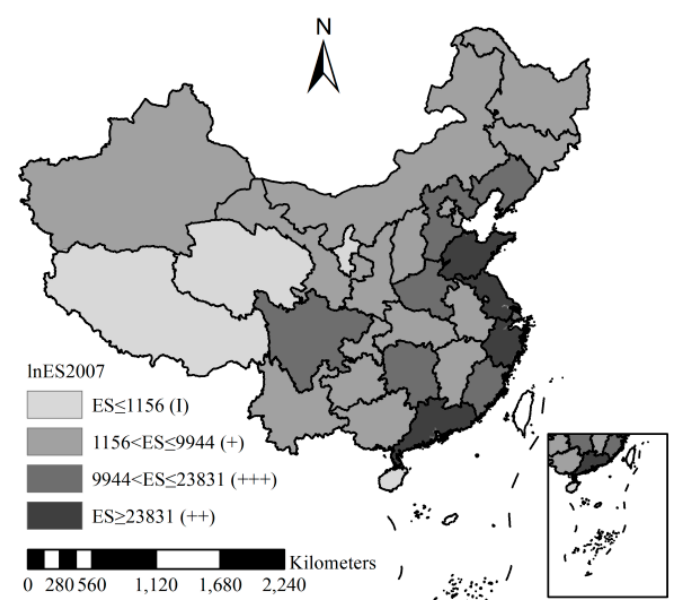

(a)

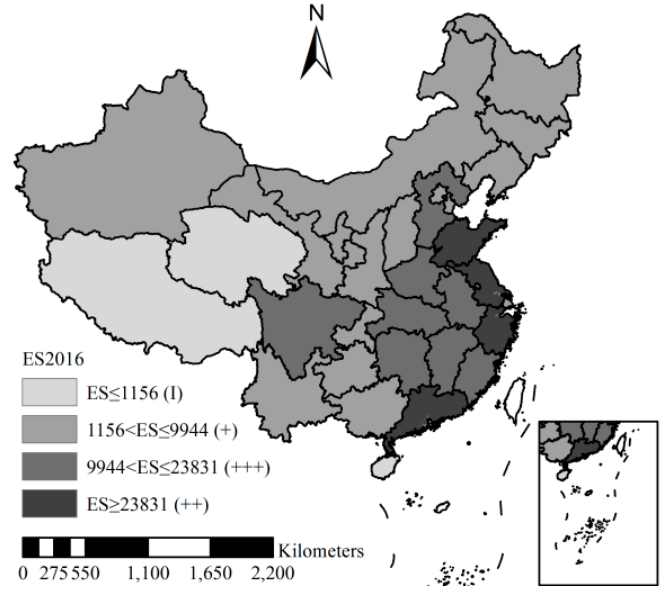

(b)

Figure 6. The regional distribution of ES relative to the impact of diversified agglomeration on EIE. (a) The regional distribution of the ES in 2007; (b) the regional distribution of the ES in 2016. Figures in parentheses represent the impact of specialized agglomeration on EIE. "I" represents that the impact is insignificant; "-"represents that the impact is negative; "+" represents that the impact is positive.

From the perspective of sub-regions, the distributions of the ES in the central region, especially the provinces of Jiangxi, Anhui, and Hubei, are becoming significantly better, while those in the eastern region, especially the provinces of Shanghai and Liaoning, are becoming worse. This change is related to China's industrial transfer policy that has shifted resources from the eastern region to the central and western regions. Moreover, the change objectively reflects the problem of improper regional selection or excessive transfer in the process of industrial transfer. At present, only the ES of Hebei, Fujian, Hunan, Henan, Jiangxi, Anhui, Hubei, and Sichuan are in the relative optimal range. There is still much room for more than $70 \%$ of provinces to increase their EIE by improving the layout of manufacturing specialized and diversified agglomeration.

\subsubsection{Robustness Test}

A robustness test is done to the results from the perspective of replacing the core indicator of EIE. First, the EIE is re-estimated with Super-EBM (Epsilon-Based Measure) model that not only considers super-efficiency but also combines radial ratio and non-radial slacks. Then, the threshold effect tests and panel threshold regressions of Models 1 and 2 are performed again. The threshold effect significant results estimation in Table 8 demonstrates that at a significant level of $10 \%$, both specialization agglomeration and diversification agglomeration have significant three-threshold effects on EIE, which is consistent with the conclusion in Table 6. The threshold values all pass the authenticity tests because the LR values are all less than 7.35. Given the length of this paper, the LR graphs showing the results of the authenticity tests of the threshold values are omitted here.

The robustness test results of Models 1 to 4 are shown in Table 9. According to the results of Model 1, after $\ln E S$ exceeds the first significant threshold, specialization agglomeration first has a significant inhibitory effect on EIE, and then the effect becomes insignificant with the increase of $\ln E S$. When $\ln E S$ reaches the third threshold, specialization agglomeration begins to promote the improvement of EIE. As for the results of Model 2 , when $\ln E S$ reaches the first significant threshold, the diversified agglomeration has a positive promotion effect on EIE, and the effect is first strengthened and then weakened with the increase of $\ln E S$. There are some slight changes in the coefficients and significance of the relevant variables, but generally speaking, the overall results are basically consistent with Table 7. Besides, the results of Models 3 and 4 are similar to those of Table 7. Therefore, our empirical results are reliable and stable. 
Table 8. Robustness check: results of threshold effect and test.

\begin{tabular}{|c|c|c|c|c|c|c|c|c|c|}
\hline Model & $\begin{array}{l}\text { Threshold } \\
\text { Variable }\end{array}$ & $\begin{array}{c}\text { Threshold } \\
\text { Model }\end{array}$ & F-value & $p$-Value & $1 \%$ & $5 \%$ & $10 \%$ & $\begin{array}{l}\text { Threshold } \\
\text { Estimates }\end{array}$ & $\begin{array}{c}95 \% \\
\text { Confidence } \\
\text { Interval }\end{array}$ \\
\hline \multirow{4}{*}{ Model 1} & \multirow{4}{*}{$\ln E S$} & \multirow{4}{*}{$\begin{array}{c}\text { Single-threshold } \\
\text { Double- } \\
\text { threshold } \\
\text { Three-threshold }\end{array}$} & $23.186^{* * *}$ & 0.010 & 24.681 & 14.201 & 8.001 & 0.551 & {$[0.551,2.297]$} \\
\hline & & & \multirow{2}{*}{$31.803^{* * *}$} & \multirow{2}{*}{0.000} & \multirow{2}{*}{14.064} & \multirow{2}{*}{8.252} & \multirow{2}{*}{6.020} & 0.551 & {$[0.551,0.551]$} \\
\hline & & & & & & & & 2.297 & {$[2.297,2.297]$} \\
\hline & & & $7.645^{*}$ & 0.084 & 19.221 & 10.557 & 6.964 & 3.744 & {$[0.984,3.955]$} \\
\hline \multirow{4}{*}{ Model 2} & \multirow{4}{*}{$\ln E S$} & \multirow{4}{*}{$\begin{array}{l}\text { Single-threshold } \\
\text { Double- } \\
\text { threshold } \\
\text { Three-threshold }\end{array}$} & $14.268^{* *}$ & 0.038 & 27.678 & 11.512 & 7.950 & 3.359 & {$[-0.705,3.753]$} \\
\hline & & & 1125 * & 0066 & 8996 & 2218 & 0063 & 1.154 & {$[-0.705,2.386]$} \\
\hline & & & $1.125^{*}$ & 0.066 & 8.996 & 2.218 & 0.063 & 3.171 & {$[0.551,3.744]$} \\
\hline & & & $11.996^{* *}$ & 0.048 & 22.889 & 11.946 & 8.122 & 2.297 & {$[0.551,3.753]$} \\
\hline
\end{tabular}

Note: ${ }^{*} p<0.1,{ }^{* *} p<0.05,{ }^{* * *} p<0.01$.

Table 9. Robustness check: results of Models 1 to 4 .

\begin{tabular}{|c|c|c|c|c|c|c|c|}
\hline Variable & Model 1 & Variable & Model 2 & Variable & Model 3 & Variable & Model 4 \\
\hline $\ln S P(\ln E S \leq 0.551)$ & $\begin{array}{l}0.031 \\
(0.81)\end{array}$ & $\ln D I(\ln E S \leq 1.154)$ & $\begin{array}{l}-0.294^{* *} \\
(-2.13)\end{array}$ & $\ln (S P)^{3}$ & $\begin{array}{l}0.029 \\
(0.59)\end{array}$ & $\ln (S P)^{2}$ & $\begin{array}{l}-0.094 * \\
(-1.94)\end{array}$ \\
\hline $\begin{array}{c}\ln S P(0.551<\ln E S \\
\leq 2.297)\end{array}$ & $\begin{array}{c}-0.086^{* * *} \\
(-2.67)\end{array}$ & $\begin{array}{c}\ln D I(1.154<\ln E S \\
\leq 3.317)\end{array}$ & $\begin{array}{c}0.177^{* * *} \\
(2.96)\end{array}$ & $\ln (S P)^{2}$ & $\begin{array}{l}-0.249 \\
(-1.10)\end{array}$ & $\ln S P$ & $\begin{array}{l}0.215 \\
(1.62)\end{array}$ \\
\hline $\begin{array}{c}\ln S P(2.297<\ln E S \\
\leq 3.744)\end{array}$ & $\begin{array}{l}0.072 \\
(1.61)\end{array}$ & $\begin{array}{c}\ln D I(3.317<\ln E S \\
\leq 3.359)\end{array}$ & $\begin{array}{l}0.286^{* * *} \\
(5.07)\end{array}$ & $\ln S P$ & $\begin{array}{l}0.475 \\
(1.43)\end{array}$ & $\ln (D I)^{2}$ & $\begin{array}{l}0.168^{* *} \\
(2.11)\end{array}$ \\
\hline $\ln S P(\ln E S \geq 3.744)$ & $\begin{array}{l}0.124^{* *} \\
(2.44)\end{array}$ & $\ln D I(\ln E S \geq 3.359)$ & $\begin{array}{l}0.167^{*} \\
(1.78)\end{array}$ & $\ln (D I)^{3}$ & $\begin{array}{l}-0.451^{* * *} \\
(-2.59)\end{array}$ & $\ln D I$ & $\begin{array}{l}0.008 \\
(0.07)\end{array}$ \\
\hline $\ln E L$ & $\begin{array}{l}-0.025^{*} \\
(-1.66)\end{array}$ & $\ln E L$ & $\begin{array}{l}-0.052^{* * *} \\
(-2.98)\end{array}$ & $\ln (D I)^{2}$ & $\begin{array}{l}0.964^{* * *} \\
(3.05)\end{array}$ & $\ln E L$ & $\begin{array}{l}-0.050^{* * *} \\
(-2.78)\end{array}$ \\
\hline $\ln E R$ & $\begin{array}{l}-0.010 \\
(-1.23)\end{array}$ & $\ln E R$ & $\begin{array}{l}-0.010 \\
(-1.21)\end{array}$ & $\ln D I$ & $\begin{array}{l}-0.317^{*} \\
(-1.81)\end{array}$ & $\ln E R$ & $\begin{array}{l}-0.123 \\
(-1.45)\end{array}$ \\
\hline $\ln I C$ & $\begin{array}{l}0.028 * * \\
(2.05)\end{array}$ & $\ln I C$ & $\begin{array}{c}0.043^{* * *} \\
(3.06)\end{array}$ & $\ln E L$ & $\begin{array}{l}-0.045^{* *} \\
(-2.51)\end{array}$ & $\ln I C$ & $\begin{array}{c}0.055^{* * *} \\
(3.86)\end{array}$ \\
\hline $\ln I I$ & $\begin{array}{l}0.052 * \\
(1.81)\end{array}$ & $\ln I I$ & $\begin{array}{l}0.048 \\
(1.60)\end{array}$ & $\ln E R$ & $\begin{array}{l}-0.011 \\
(-1.36)\end{array}$ & $\ln I I$ & $\begin{array}{l}0.017 \\
(0.55)\end{array}$ \\
\hline $\ln O L$ & $\begin{array}{l}-0.041 \text { ** } \\
(-2.39)\end{array}$ & $\ln O L$ & $\begin{array}{l}-0.037^{* *} \\
(-1.99)\end{array}$ & $\ln I C$ & $\begin{array}{c}0.062^{* * *} \\
(4.30)\end{array}$ & $\ln O L$ & $\begin{array}{l}-0.057^{* * *} \\
(-3.05)\end{array}$ \\
\hline \multirow[t]{3}{*}{ Constant } & $\begin{array}{l}-0.431 * * * \\
(-4.44)\end{array}$ & Constant & $\begin{array}{l}-0.457^{* * * *} \\
(-5.16)\end{array}$ & $\ln I I$ & $\begin{array}{l}0.021 \\
(0.67)\end{array}$ & Constant & $\begin{array}{l}-0.540^{* * * *} \\
(-3.72)\end{array}$ \\
\hline & & & & $\ln O L$ & $\begin{array}{l}-0.054^{* * *} \\
(-2.91)\end{array}$ & & \\
\hline & & & & Constant & $\begin{array}{c}-0.632^{* * *} \\
(-3.43)\end{array}$ & & \\
\hline
\end{tabular}

Note: Figures in parentheses are t values; ${ }^{*} p<0.1,{ }^{* *} p<0.05,{ }^{* * *} p<0.01$.

\section{Discussion}

\subsection{Reasons of the Nonlinear Impacts of Different Agglomeration Patterns on EIE}

Refer to the life cycle theory of agglomeration, the specialized and diversified agglomeration process can be divided into the budding period, growth period, mature period, and recession period. In the beginning, specialized agglomeration and diversified agglomeration are both in their budding period, the number of enterprises in the agglomeration area is relatively small, various resources and supporting facilities are relatively lacking, the manufacturing chain is just beginning to take shape and the cluster effect is not obvious, thus, the impacts of specialized and diversified agglomeration on EIE are both not significant. As the agglomeration continues to deepen, specialized agglomeration and diversified agglomeration gradually enter their growth and mature period. Because of the different influence mechanisms, they have different effects on EIE. 


\subsubsection{Reasons of the U-Shaped Impact of Specialized Agglomeration on EIE}

The result of Model 1 shows that after the ES exceeds the threshold value of 1735 enterprises, the relationship between specialized agglomeration and EIE is a U-shaped form. On the left side of the U-shaped curve, specialized agglomeration is not conducive to the increase of EIE. The possible reasons are as follows. First, with the deepening of manufacturing specialized agglomeration, especially that of polluting manufacturing industries, the environmental pollution in clustered regions is aggravated. Simultaneously, the competition among enterprises in the same industry is intensified. Since the relevant policies and facilities in the regions are not yet complete at this time, the low-level homogeneous competition will lead to the repeated construction of enterprises and the blind investment in eco-innovation. Low resource utilization and high consumption exacerbate ecological problems and lower the EIE. Second, since the enterprises in the same industry adopt monopoly or confidential measures on core technologies, the overflow of explicit and tacit knowledge between enterprises is mostly noncore. Therefore, in the growth period of specialized agglomeration, although the scale economy effect and the homogeneous knowledge spillover effect begin to appear, they are less effective in promoting the EIE than the negative externalities of the environment in reducing the EIE. Hence, the specialized agglomeration has an inhibiting effect on the improvement of EIE.

On the right side of the U-shaped curve, specialized agglomeration is conducive to the increase of EIE. First, in this stage, specialized agglomeration gradually evolves from the growth period to the mature period. As the industrial chain gradually becomes complete in the agglomeration regions, effective cooperation between upstream and downstream enterprises reduces transportation and transaction costs and improves the efficiency of resource utilization. Moreover, policies and facilities in the regions continue to be better, which also optimizes the external environment for enterprises to conduct eco-innovation. Those improvements contribute to the increase of EIE. Second, with the increase in the number of enterprises, competition and environmental pollution issues become more and more severe. The deterioration of the environment forces governments to take stricter regulatory measures, increasing the enterprises' environmental costs and the consumers' demand for environmentally friendly products [67]. These factors further push enterprises to add investment in eco-innovation and increase EIE to obtain more competitive advantages and profits $[68,69]$. Third, since specialized agglomeration enterprises belong to the same industry, the pollutants produced by the production and operation are similar. A scale economy effect can be achieved by the specialized operation of public pollution control facilities. Fourth, the stricter environmental regulatory measures and the increase in the investment in environmental governance will also alleviate the environmental pollution in the regions to a certain extent. When the ES is on the right side of the U-shaped curve, the cooperation effect, the competition effect, and the scale economy effect brought by specialized agglomeration is enhanced, while the inhibitory effect caused by the negative externality of the environment on EIE is weakened. Compared with the inhibitory effect, the promotion effect becomes a dominant one, thus the specialized agglomeration has a positive impact on the EIE.

\subsubsection{Reasons of the S-Shaped Impact of Diversified Agglomeration on EIE}

The result of Model 2 reflects that after the ES exceeds the threshold value of 1156 enterprises, the relationship between diversified agglomeration and EIE is an S-shaped form. In the first stage of the S-shaped curve, diversified agglomeration is in its growth period. On the one hand, the agglomeration of enterprises in various industries causes an increase in environmental pollution and resource consumption, which are not conducive to the improvement of EIE. On the other hand, since the agglomerated enterprises belong to different industries, the competition among enterprises in terms of technology, resources, and talents is relatively small and there are less wasted resources due to repeated construction and other reasons. Moreover, the construction and improvement of public facilities and equipment can increase resource utilization and energy efficiency [70]. The increasingly 
frequent technical collaboration and communication between enterprises facilitate the overflow of heterogeneous knowledge. Barbieri et al. [55] pointed out that diversification is the main driver of the development of green technology in the early stages of the technology life cycle. The heterogeneous knowledge spillover generated by diversified agglomeration can effectively promote $E I E$, and the promotion effect is greater than the inhibition effect of negative environmental externalities on the EIE. Therefore, the influence coefficient of diversified agglomeration on EIE is positive and significant.

In the second stage of the S-shaped curve, the promotion effect of diversified agglomeration on EIE is enhanced. The possible reasons are as follows. First, the first batch of enterprises in the agglomeration area uses first-mover advantages to obtain excess profits, which in turn attracts more manufacturing enterprises to settle in the agglomeration area. As the number of enterprises in different industries continues to increase, the diversified agglomeration degree of the regions deepens, and the diversified agglomeration gradually enters the mature period. The scale economy effect, knowledge spillover effect, and cooperative effect are intensified, and the promotion effect of diversified agglomeration is strengthened. Second, after the accumulation of technological innovation in the last stage, enterprises in the regions already have some relatively mature and advanced green innovation technologies [71]. Besides, as relevant government support and environmental regulation measures are improved, the enterprises' environmental awareness is strengthened. Based on the internal and external conditions of the agglomeration areas, the enterprises continuously improve their eco-innovation technologies and pollution control capabilities to facilitate long-term development. These increase the positive externalities of the technology and reduce the negative externalities of the environment, which is conducive to the improvement of the EIE.

In the third stage of the S-shaped curve, the promotion effect of diversified agglomeration on EIE is reduced slightly. Due to the limited resource carrying capacity of the agglomeration areas, when the number of enterprises in the agglomeration regions is saturated, the crowding effect appears and the diversified agglomeration gradually enters the recession period. At this stage, there is a shortage of resources such as land and energy. The fierce competition of enterprises for limited resources increases enterprises' costs. Owing to the increasing costs, enterprises may reduce or even stop eco-innovation for survival or more profits. To prevent the pressure from the increasing resource competition, enterprises in the agglomeration regions may also block the entry of new ones. The inflow of new knowledge is hindered by such a self-blocking mechanism, causing the lock-in of regional technologies [49]. Thereby, the promotion effect of diversified agglomeration on the EIE is weakened.

\subsection{Strengths and Limitations}

Improving EIE is a significant way for China to achieve economic high-quality development and obtain sustainable international competitive advantages. With the implementation of China's urban agglomeration strategy and the emergence of China's manufacturing agglomeration characteristics, the impact of manufacturing agglomeration on the EIE gradually becomes a hot research topic. The contribution of this paper is mainly manifested in two aspects. First, considering the heterogeneity of manufacturing subindustries, we divided manufacturing agglomeration patterns into specialized and diversified agglomeration and studied the impact of different agglomeration patterns on EIE by using Chinese data of 21 manufacturing subindustries. Second, from the perspective of the dynamic evolution of manufacturing agglomeration, we conduct a nonlinear test on the relationships between different manufacturing agglomeration patterns and EIE.

Several limitations in this paper can be solved in future studies. Firstly, manufacturing agglomeration is based on geographical proximity, so the flow of eco-innovation elements and environmental pollutants among different regions may have a spatial correlation. Our next step is to take into account the spatial dependence and examine the effect of spatial factors on EIE. Secondly, since the study is conducted from the perspective of 
the dynamic evolution of manufacturing agglomeration, the data used should cover a long period. Nevertheless, owing to the limitations of data acquisition of manufacturing subindustries in the China Industrial Statistical Yearbook, we can only calculate the level of specialized and diversified agglomerations from 2007 to 2016. Future studies can try to find proper surrogate variables or indicators and perform regression analysis with data in a longer or more recent period so that the results can be more accurate. Thirdly, it is worth noting that the selection of indicators plays a key role in the conclusions. Although we have replaced part of the indicators in the robustness test, it may remain insufficient. For example, industrial output value and employment figure can both be adopted to calculate the variables of specialized and diversified agglomeration. It needs to further discuss that whether the conclusions will be different if other variables or indicators are chosen for regression.

\section{Conclusions and Recommendations}

By using the Super-SBM model with undesirable outputs, this paper measures the level of EIE in 30 provinces of China, except Macao, Taiwan, Hong Kong, and Tibet. Considering the heterogeneity of manufacturing subindustries and the dynamic evolution of agglomeration, this paper distinguishes different agglomeration patterns and adopts the panel threshold regression model to empirically test the nonlinear effects of specialized and diversified agglomeration on EIE. The main findings are as follows:

Firstly, China's EIE shows a U-shaped changing trend and its spatial distribution represents significant regional heterogeneity. The EIE of the eastern region, especially Beijing and Zhejiang, is far ahead of that of central and western regions.

Secondly, from the perspective of the dynamic evolution of manufacturing agglomeration, the impacts of both specialized and diversified agglomeration on EIE are nonlinear and have significant three-threshold effects. Owing to the differences in the influence mechanism, specialized and diversified agglomeration exert very different effects on EIE. For the impact of specialized agglomeration on EIE, three turning points occur when the ES reaches 555 enterprises, 1735 enterprises, and 9944 enterprises, respectively. After the ES exceeds the threshold value of 1735 enterprises, the relationship between specialized agglomeration and EIE is U-shaped, suggesting that the specialized agglomeration will inhibit first and then promote the increase of EIE. For the impact of diversified agglomeration on EIE, three turning point occurs when the ES reaches 1156 enterprises, 9944 enterprises, and 23,831 enterprises, respectively. After ES passes the threshold value of 1156 enterprises, the relationship between diversified agglomeration and EIE is S-shaped, indicating that the diversified agglomeration can stimulate the increase of EIE and the promoting effect will increase first and then decrease.

Thirdly, in terms of eco-innovation, the development of diversified agglomeration is superior to that of specialized agglomeration. Regarding the comprehensive impact of specialized and diversified agglomeration on EIE, the overall distribution of ES in China has been slightly optimized. As for the sub-regions, the distribution of ES in the central region is becoming significantly better, while in the eastern region, the distribution is becoming worse. Overall, there is still much room for more than $70 \%$ of provinces to increase their EIE by improving the layout of manufacturing specialized and diversified agglomeration.

Given the above conclusions, we propose the following policy recommendations:

Firstly, based on the characteristics of each evolutionary stage of manufacturing agglomeration, a dynamic approach and differentiated policies of agglomeration should be introduced. In the budding period, the government should focus on increasing the number of enterprises, actively guiding the construction of industrial zones, and releasing supporting policies. In the growth period, given the significant positive effect of manufacturing diversified agglomeration on EIE, measures should be taken to encourage the geographical gathering of enterprises in different industries. In the mature period, manufacturing diversified and specialized agglomeration should both be valued. In this stage, 
it is very vital to identify the leading industries in different regions, guide innovation funds and talents to gather in industries with comparative advantages, and strengthen the cooperation of enterprises. Moreover, when the agglomeration level is too high, the spatial transfer strategy of labor-intensive and capital-intensive industries might be implemented to alleviate the negative impact of the crowding effect.

Secondly, differentiated manufacturing agglomeration patterns and agglomeration degrees should be selected in various regions. For example, for regions such as Hebei, Jiangsu, Zhejiang, Fujian, Shandong, Guangdong, Hunan, Henan, Jiangxi, Anhui, Hubei, and Sichuan, the level of both specialized and diversified agglomeration should be enhanced. For regions such as Tianjin, Beijing, Shanghai, Liaoning, Heilongiang, Shanxi, Jilin, Gansu, Guizhou, Yunnan, Inner Mongolia, Shaanxi, Chongqing, Guangxi, Xinjiang, improving the diversified agglomeration level is the key to promoting EIE. For regions such as Hainan and Qinghai, since they have a small manufacturing scale and immature development conditions, it is better to improve infrastructure and public services, encourage the agglomeration of enterprises in different sectors, and promote the cross-industry flow of green innovation elements.

Thirdly, China should pay attention to strengthening the driving mechanism of ecoinnovation and the development quality of the manufacturing industry. On the one hand, the regions should raise their quality threshold for introducing foreign enterprises to avoid becoming pollution refuges. On the other hand, it is of great importance to accelerate the transformation of the traditional manufacturing industry and the industrialization of emerging technologies. Furthermore, the GDP evaluation mechanism of governments should be reasonably diluted. Indicators related to EIE can be properly added to the governments' performance evaluation system to alleviate energy and environmental problems caused by the excessive pursuit of GDP growth. For example, in policy evaluation, the EIE, green technology level, energy inputs, and undesirable outputs can be assessed in each sector and along all stages of economic development.

Author Contributions: Methodology, Q.Z. and S.W.; data curation, L.Z. and S.H.; writing-original draft preparation, L.Z.; writing-review and editing, L.Z. and R.M.; funding acquisition, R.M. All authors have read and agreed to the published version of the manuscript.

Funding: This study was supported by the Chinese National Funding of Social Sciences (grant no.17BGL209) and the Fundamental Research Funds for the Central Universities (grant no. 2019-JL-005).

Institutional Review Board Statement: Not applicable.

Informed Consent Statement: Not applicable.

Data Availability Statement: Publicly available datasets were analyzed in this study. This data can be found here: Big data research platform for China's economy and society. Available online: https: / / data.cnki.net/Yearbook/Navi?type=type\&code=A (accessed on 1 August 2020).

Conflicts of Interest: The authors declare no conflict of interest.

\section{Appendix A}

Table A1. List of 21 manufacturing sub-industries in China.

\begin{tabular}{cc}
\hline No. & Manufacturing Sub-Industries \\
\hline 1 & Agricultural and sideline food processing industry \\
2 & Food manufacturing industry \\
3 & Wine, beverage and refined tea manufacturing industry \\
4 & Tobacco products industry \\
5 & Textile industry \\
6 & Textile, clothing and apparel industry \\
7 & Paper and paper products industry \\
8 & Petroleum processing, coking and nuclear fuel processing industry \\
9 & Chemical raw materials and chemical products manufacturing industry \\
\hline
\end{tabular}


Table A1. Cont.

\begin{tabular}{cc}
\hline No. & Manufacturing Sub-Industries \\
\hline 10 & Pharmaceutical manufacturing industry \\
11 & Chemical fiber manufacturing industry \\
12 & Non-metallic mineral products industry \\
13 & Ferrous metal smelting and rolling processing industry \\
14 & Non-ferrous metal smelting and rolling processing industry \\
15 & Metal products industry \\
16 & General equipment manufacturing industry \\
17 & Special equipment manufacturing industry \\
18 & Transportation equipment manufacturing industry \\
19 & Electrical machinery and equipment manufacturing industry \\
20 & Computer, communication and other electronic equipment manufacturing industry \\
21 & Instrument manufacturing industry \\
\hline
\end{tabular}

\section{References}

1. $\quad$ Leung, K.M.Y.; Yeung, K.W.Y.; You, J.; Choi, K.; Zhang, X.; Smith, R.; Zhou, G.; Yung, M.M.N.; Arias-Barreiro, C.; An, Y.; et al. Toward sustainable environmental quality: Priority research questions for Asia. Environ. Toxicol. Chem. 2020, 39, 1485-1505. [CrossRef] [PubMed]

2. Wendling, Z.A.; Emerson, J.W.; de Sherbinin, A.; Esty, D.C.; Hoving, K.; Ospina, C.D.; Murray, J.; Gunn, L.; Ferrato, M.; Schreck, M.; et al. 2020 Environmental Performance Index; Yale Center for Environmental Law \& Policy: New Haven, CT, USA, 2020 ; p. 18.

3. Long, X.L.; Sun, C.W.; Wu, C.; Chen, B.; Boateng, K.A. Green innovation efficiency across China's 30 provinces: Estimate, comparison, and convergence. Mitig. Adapt. Strateg. Glob. Chang. 2020, 25, 1243-1260. [CrossRef]

4. Wang, L.; Chang, H.L.; Rizvi, S.K.A.; Sari, A. Are eco-innovation and export diversification mutually exclusive to control car-bon emissions in G-7 countries? J. Environ. Manag. 2020, 270, 110829. [CrossRef]

5. Hazarika, N.; Zhang, X.L. Evolving theories of eco-innovation: A systematic review. Sustain. Prod. Consum. 2019, 19, 64-78. [CrossRef]

6. Diaz-Garcia, C.; Gonzalez-Moreno, A.; Saez-Martinez, F.J. Eco-innovation: Insights from a literature review. Innovation 2015, 17, 6-23. [CrossRef]

7. Gente, V.; Pattanaro, G. The place of eco-innovation in the current sustainability debate. Waste Manag. 2019, 88, 96-101. [CrossRef] [PubMed]

8. Aldieri, L.; Ioppolo, G.; Vinci, C.P.; Yigitcanlar, T. Waste recycling patents and environmental innovations: An economic analy-sis of policy instruments in the USA, Japan and Europe. Waste Manag. 2019, 95, 612-619. [CrossRef] [PubMed]

9. Losacker, S.; Liefner, I. Regional lead markets for environmental innovation. Environ. Innov. Soc. Transit. 2020, 37, 120-139. [CrossRef]

10. Liao, Z.J. Content analysis of China's environmental policy instruments on promoting firms' environmental innovation. Environ. Sci. Policy 2018, 88, 46-51. [CrossRef]

11. Owen, R.; Brennan, G.; Lyon, F. Enabling investment for the transition to a low carbon economy: Government policy to finance early stage green innovation. Curr. Opin. Environ. Sustain. 2018, 31, 137-145. [CrossRef]

12. Ben Arfi, W.; Hikkerova, L.; Sahut, J.M. External knowledge sources, green innovation and performance. Technol. Forecast. Soc. Chang. 2018, 129, 210-220. [CrossRef]

13. Li, D.Y.; Tang, F.; Jiang, J.L. Does environmental management system foster corporate green innovation? The moderating effect of environmental regulation. Technol. Anal. Strateg. Manag. 2019, 31, 1242-1256. [CrossRef]

14. Todtling, F. Sustainable Innovation and Regional Developent-Rethinking Innovative Milieus. Pap. Reg. Sci. 2017, 96, 896-898. [CrossRef]

15. Juntunen, J.K.; Halme, M.; Korsunova, A.; Rajala, R. Strategies for integrating stakeholders into sustainability innovation: A Configurational Perspective. J. Prod. Innov. Manag. 2019, 36, 331-355. [CrossRef]

16. Hojnik, J.; Ruzzier, M. What drives eco-innovation? A review of an emerging literature. Environ. Innov. Soc. Trans. 2016, 19, 31-41. [CrossRef]

17. Mazzanti, M. Eco-innovation and sustainability: Dynamic trends, geography and policies. J. Environ. Plan. Manag. 2018, 61, 1851-1860. [CrossRef]

18. Fethi, S.; Rahuma, A. The impact of eco-innovation on $\mathrm{CO} 2$ emission reductions: Evidence from selected petroleum companies. Struct. Chang. Econ. Dyn. 2020, 53, 108-115. [CrossRef]

19. Geng, D.Y.; Lai, K.H.; Zhu, Q.H. Eco-innovation and its role for performance improvement among Chinese small and mediumsized manufacturing enterprises. Int. J. Prod. Econ. 2021, 231, 107869. [CrossRef]

20. Li, G.P.; Wang, X.Y.; Su, S.B.; Su, Y. How green technological innovation ability influences enterprise competitiveness. Technol. Soc. 2019, 59, 101136. [CrossRef] 
21. Kiefer, C.P.; Gonzalez, P.D.; Carrillo-Hermosilla, J. Drivers and barriers of eco-innovation types for sustainable transitions: A quantitative perspective. Bus. Strateg. Environ. 2019, 28, 155-172. [CrossRef]

22. Pacheco, D.A.D.; ten Caten, C.S.; Jung, C.F.; Navas, H.V.G.; Cruz-Machado, V.A. Eco-innovation determinants in manufactur-ing SMEs from emerging markets: Systematic literature review and challenges. J. Eng. Technol. Manag. 2018, 48, 44-63. [CrossRef]

23. Mavi, R.K.; Saen, R.F.; Goh, M. Joint analysis of eco-efficiency and eco-innovation with common weights in two-stage network DEA: A big data approach. Technol. Forecast. Soc. Chang. 2019, 144, 553-562. [CrossRef]

24. New Development Concepts Set to Shape China's Image. Available online: http://www.chinadaily.com.cn/regional/2016-10/17 / content_27094657.htm (accessed on 17 October 2016).

25. 14th Five-Year Plan's Ambitious Goals Will Upgrade Industry, Lifestyles. Available online: http:/ /www.chinadaily.com.cn/a/20 2011/30/WS5fc45d55a31024ad0ba985b7.html (accessed on 30 November 2020).

26. Zeng, W.P.; Li, L.; Huang, Y. Industrial collaborative agglomeration, marketization, and green innovation: Evidence from China's provincial panel data. J. Clean. Prod. 2021, 279, 123598. [CrossRef]

27. Kesidou, E.; Wu, L.C. Stringency of environmental regulation and eco-innovation: Evidence from the eleventh Five-Year Plan and green patents. Econ. Lett. 2020, 190, 109090. [CrossRef]

28. Rabelo, O.D.S.; Melo, A.S.S.D. Drivers of multidimensional eco-innovation: Empirical evidence from the Brazilian industry. En-viron. Technol. 2019, 40, 2556-2566. [CrossRef] [PubMed]

29. Bitat, A. Environmental regulation and eco-innovation: The Porter hypothesis refined. Eurasian Bus. Rev. 2018, 8, $299-321$. [CrossRef]

30. Arranz, N.; Arroyabe, C.F.; de Arroyabe, J.C.F. The effect of regional factors in the development of eco-innovations in the firm. Bus. Strateg. Environ. 2019, 28, 1406-1415. [CrossRef]

31. Pan, X.; Sinha, P.; Chen, X.J. Corporate social responsibility and eco-innovation: The triple bottom line perspective. Corp. Soc. Responsib. Environ. Manag. 2021, 28, 214-228. [CrossRef]

32. Segarra-Ona, M.D.; Peiro-Signes, A.; Mondejar-Jimenez, J.; Vargas-Vargas, M. Service vs. manufacturing: How to address more effectively eco-innovation public policies by disentangling the different characteristics of industries. Innov. Eur. J. Soc. Sci. Res. 2014, 27, 134-151. [CrossRef]

33. Yuan, H.X.; Feng, Y.D.; Lee, C.C.; Cen, Y. How does manufacturing agglomeration affect green economic efficiency? Energy Econ. 2020, 92, 104944. [CrossRef]

34. Verhoef, E.T.; Nijkamp, P. Externalities in urban sustainability: Environmental versus localization-type agglomeration externalities in a general spatial equilibrium model of a single-sector monocentric industrial city. Ecol. Econ. 2002, 40, 157-179. [CrossRef]

35. Zheng, Q.; Lin, B. Impact of industrial agglomeration on energy efficiency in China's paper industry. J. Clean. Prod. 2018, 184, 1072-1080. [CrossRef]

36. Liu, Z.; Cai, Y.; Hao, X. The agglomeration of manufacturing industry, innovation and haze pollution in China: Theory and evidence. Int. J. Environ. Res. Public Health 2020, 17, 1670. [CrossRef] [PubMed]

37. Speldekamp, D.; Knoben, J.; Saka-Helmhout, A. Clusters and firm-level innovation: A configurational analysis of agglomeration, network and institutional advantages in European aerospace. Res. Policy 2020, 49, 103921. [CrossRef]

38. Sheng, Y.; Zhao, J.; Zhang, X.; Song, J.; Miao, Y. Innovation efficiency and spatial spillover in urban agglomerations: A case of the Beijing-Tianjin-Hebei, the Yangtze River Delta, and the Pearl River Delta. Growth Chang. 2019, 50, 1280-1310. [CrossRef]

39. Hasan, S.; Faggian, A.; Klaiber, H.A.; Sheldon, I. Agglomeration economies or selection? An analysis of taiwanese science parks. Int. Reg. Sci. Rev. 2018, 41, 335-363. [CrossRef]

40. Li, L.; Lei, L.; Han, D. Regional green innovation efficiency in high-end manufacturing. J. Coast. Res. 2018, 82, 280-287. [CrossRef]

41. Yi, M.; Wang, Y.; Yan, M.; Fu, L.; Zhang, Y. Government R\&D subsidies, environmental regulations, and their effect on green innovation efficiency of manufacturing industry: Evidence from the Yangtze River Economic Belt of China. Int. J. Environ. Res. Public Health 2020, 17, 1330. [CrossRef]

42. Jirčikova, E.; Pavelkova, D.; Bialic-Davendra, M.; Homolka, L. The age of clusters and its influence on their activity preferences. Technol. Econ. Dev. Econ. 2013, 19, 621-637. [CrossRef]

43. Schumpeter, J. The Theory of Economic Development; The Commercial Press: Beijing, China, 1990; pp. 53-89.

44. Cobb, C.W.; Douglas, P.H. A theory of production. Am. Econ. Rev. 1928, 18, 139-165.

45. Chen, W.L.; Huang, X.J.; Liu, Y.H.; Luan, X.; Song, Y. The impact of high-tech industry agglomeration on green economy efficiency-Evidence from the Yangtze river economic belt. Sustainability 2019, 11, 5189. [CrossRef]

46. Duranton, G. Growing through cities in developing countries. World Bank Res. Obs. 2015, 30, 39-73. [CrossRef]

47. Asheim, B.T.; Isaksen, A. Location, agglomeration and innovation: Towards regional innovation systems in Norway? Eur. Plan. Stud. 1997, 5, 299-330. [CrossRef]

48. Bottazzi, L.; Peri, G. Innovation and spillovers in regions: Evidence from European patent data. Eur. Econ. Rev. 2003, 47, 687-710. [CrossRef]

49. Shen, N.; Zhao, Y.; Wang, Q. Diversified agglomeration, specialized agglomeration, and emission reduction effect-A non-linear test based on Chinese city data. Sustainability 2018, 10, 2002. [CrossRef]

50. Porter, M.E. America's green strategy. Sci. Am. 1991, 264, 168. [CrossRef]

51. Liu, J.; Cheng, Z.H.; Zhang, H.M. Does industrial agglomeration promote the increase of energy efficiency in China? J. Clean. Prod. 2017, 164, 30-37. [CrossRef] 
52. Wang, N.; Zhu, Y.M.; Yang, T.B. The impact of transportation infrastructure and industrial agglomeration on energy efficiency: Evidence from China's industrial sectors. J. Clean. Prod. 2020, 244, 118708. [CrossRef]

53. Marshall, A. Principles of Economics: An Introductory Volume, 8th ed.; The Macmillan Press: London, UK, 1920; pp. $258-290$.

54. Jacobs, J. The Economy of Cities; Vintage Press: New York, NY, USA, 1969; p. 268.

55. Barbieri, N.; Perruchas, F.; Consoli, D. Specialization, diversification, and environmental technology life cycle. Econ. Geogr. 2020, 96, 161-186. [CrossRef]

56. Hansen, B.E. Threshold effects in non-dynamic panels: Estimation, testing, and inference. J. Econom. 1999, 93, 345-368. [CrossRef]

57. Tone, K. Dealing with undesirable outputs in DEA: A slack-based measure (SBM) Approach. In Proceedings of the NAPW III, Toronto, ON, Canada, 23-25 June 2004; pp. 44-45.

58. Wei, Y.; Li, Y.; Wu, M.; Li, Y. Progressing sustainable development of "the Belt and Road countries": Estimating environmental efficiency based on the Super-slack-based measure model. Sustain. Dev. 2020, 28, 521-539. [CrossRef]

59. Zhu, Y.F.; Wang, Z.L.; Qiu, S.L.; Zhu, L.L. Effects of environmental regulations on technological innovation efficiency in China's industrial enterprises: A spatial analysis. Sustainability 2019, 11, 2186. [CrossRef]

60. Yu, Y.; Zhang, Y.; Miao, X. Impacts of dynamic agglomeration externalities on eco-efficiency: Empirical evidence from China. Int. J. Environ. Res. Public Health 2018, 15, 2304. [CrossRef] [PubMed]

61. Brunel, C.; Levinson, A. Measuring the Stringency of Environmental Regulations. Rev. Environ. Econ. Policy 2016, $10,47-67$. [CrossRef]

62. Perruchas, F.; Consoli, D.; Barbieri, N. Specialisation, diversification and the ladder of green technology development. Res. Policy 2020, 49, 103922. [CrossRef]

63. Menzel, M.-P.; Fornahl, D. Cluster life cycles-dimensions and rationales of cluster evolution. Ind. Corp. Chang. 2010, 19, 205-238. [CrossRef]

64. Claver-Cortés, E.; Marco-Lajara, B.; Manresa-Marhuenda, E. Innovation in foreign enterprises: The influence exerted by loca-tion and absorptive capacity. Technol. Anal. Strateg. Manag. 2020, 32, 936-954. [CrossRef]

65. Meili, R.; Shearmur, R. Diverse diversities-Open innovation in small towns and rural areas. Growth Chang. 2019, 50, 492-514. [CrossRef]

66. Lee, B.K.; Sohn, S.Y. Disparities in exploitative and exploratory patenting performance across regions: Focusing on the roles of agglomeration externalities. Pap. Reg. Sci. 2019, 98, 241-263. [CrossRef]

67. Arroyave, J.J.; Saez-Martinez, F.J.; Gonzalez-Moreno, A. Cooperation with universities in the development of eco-innovations and firms' performance. Front. Psychol. 2020, 11, 612465. [CrossRef]

68. Kalaitzi, D.; Matopoulos, A.; Bourlakis, M.; Tate, W. Supply chains under resource pressure: Strategies for improving resource efficiency and competitive advantage. Int. J. Oper. Prod. Manag. 2019, 39, 1323-1354. [CrossRef]

69. Martínez-Zarzoso, I.; Bengochea-Morancho, A.; Morales-Lage, R. Does environmental policy stringency foster innovation and productivity in OECD countries? Energy Policy 2019, 134, 110982. [CrossRef]

70. Brinkerink, J.; Chegut, A.; Letterie, W. Energy performance and capital expenditures in manufacturing industries. Energy Effic. 2019, 12, 2011-2038. [CrossRef]

71. Hötte, K. How to accelerate green technology diffusion? Directed technological change in the presence of coevolving absorptive capacity. Energy Econ. 2020, 85, 104565. [CrossRef] 